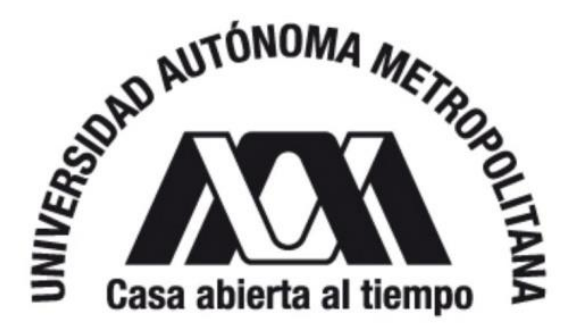

UNIVERSIDAD AUTÓNOMA METROPOLITANA

UNIDAD IZTAPALAPA

DIVISIÓN DE CIENCIAS BIOLÓGICAS Y DE LA SALUD

DEPARTAMENTO DE BIOTECNOLOGÍA

\title{
CAPACIDAD DE UN CONSORCIO NITRIFICANTE PARA BIOTRANSFORMAR LA AMPICILINA
}

\author{
TESIS \\ PARA OBTENER EL GRADO DE \\ MAESTRO EN BIOTECNOLOGÍA
}

PRESENTA

I.B.I. JOSÉ JUAN RAMÍREZ MUÑOZ

\section{COMITÉ TUTORIAL}

DIRECTORA: DRA. ANNE-CLAIRE TEXIER

ASESORA: DRA. FLOR DE MARÍA CUERVO LÓPEZ

ASESOR: DR. DIEGO IVAN BEJARANO ORTIZ

Ciudad de México

Junio del 2018 
Esta tesis se llevó a cabo en el Laboratorio de Fisiología Microbiana W-004 del Departamento de Biotecnología de la Universidad Autónoma Metropolitana unidad Iztapalapa, gracias al apoyo otorgado por el Consejo Nacional de Ciencia y Tecnología. Beca con número de registro 570256.

La Maestría en Biotecnología de la Universidad Autónoma Metropolitana está incluida en el Programa Nacional de Posgrados de Calidad (PNPC) del CONACYT, con la referencia 001465. 
El H. Jurado designado por la División de Ciencias Biológicas y de la Salud de la Universidad Autónoma Metropolitana unidad Iztapalapa aprobó la tesis

\title{
CAPACIDAD DE UN CONSORCIO NITRIFICANTE PARA BIOTRANSFORMAR LA AMPICILINA
}

\author{
Que presentó \\ IBI Jose Juan Ramírez Muñoz \\ Comité tutorial \\ Dra. Anne-Claire Texier \\ Directora, UAM-Iztapalapa \\ Dra. Flor de María Cuervo López \\ Asesora, UAM-Iztapalapa \\ Dr. Diego Ivan Bejarano Ortiz \\ Asesor, IPN-Cinvestav
}

\section{H. Jurado}

Presidenta: Dra. Flor de María Cuervo López

UAM-Iztapalapa

Secretario: Dr. Diego Ivan Bejarano Ortiz IPN-Cinvestav

Vocal: Dr. Carlos David Silva Luna

UAM-Lerma

Vocal: Dra. Emir Martínez Gutiérrez

INECOL-Xalapa 


\section{AGRADECIMIENTOS}

Agradezco la dirección de la Dra. Anne Claire Texier en la realización de esta tesis.

A la Dra. Flor de María Cuervo López y al Dr. Diego Ivan Bejarano Ortiz por su asesoría.

A los integrantes del jurado por sus comentarios y sugerencias.

A los compañeros Jenny Ruth Banda Soriano, Aarón Villaseca Hernández y Jorge Eduardo García Camacho por su apoyo en las técnicas de laboratorio. 


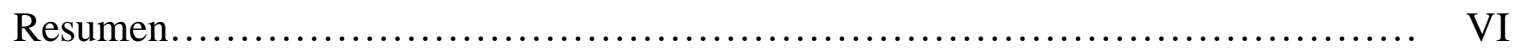

Abstract ......................................................................... VIII

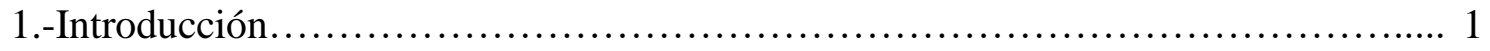

1.1 Contaminantes orgánicos emergentes (EOC) …....................... 1

1.2 Los antibióticos .............................................................. 2

1.2.1 Los betalactámicos .............................................. 4

1.2.2 La ampicilina .................................................... 6

1.3 Eliminación de contaminantes por procesos biológicos ..................... 8

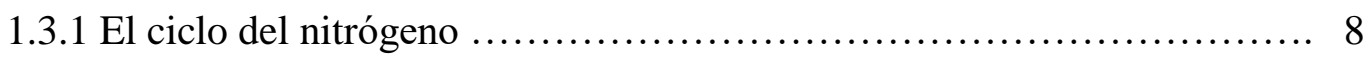

1.3.1.1 Amonio oxidación ............................................. 9

1.3.1.2 Nitrito oxidación ................................................ 10

1.3.1.3 Consorcios nitrificantes ..................................... 11

2.- Antecedentes ............................................................. 13

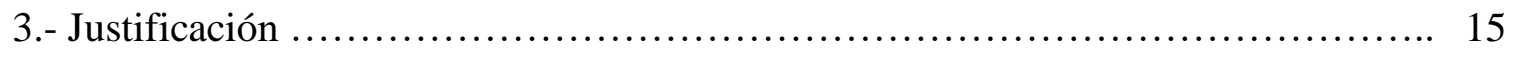

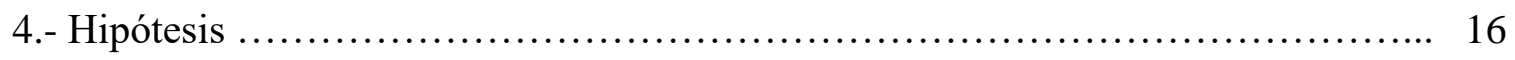

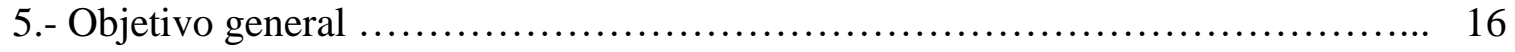

5.1 Objetivos particulares .................................................. 17

6.- Materiales y Métodos ........................................................ 17

6.1 Reactor nitrificante en continuo ...................................... 17

6.2 Cultivos nitrificantes en lote y ensayos abióticos ......................... 19

6.3 Variables de respuesta .............................................. 21

6.4 Métodos analíticos ..................................................... 22

6.4.1 Cuantificación de amonio ..................................... 22

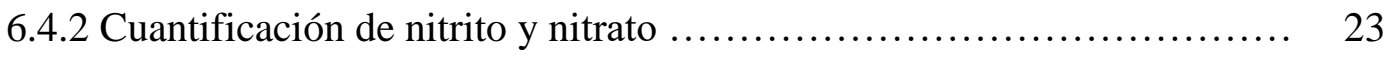

6.4.3 Cuantificación de carbono orgánico total ........................... 24

6.4.4 Cuantificación de proteína bacteriana ............................. 25

6.4.5 Cuantificación de ampicilina ..................................... 26

6.4.6 Medición de $\mathrm{pH}$ y oxígeno disuelto .................................. 26

6.4.7 Reproducibilidad y linealidad de métodos........................... 27 
7.- Resultados y discusión............................................ 27

7.1 Reactor nitrificante en continuo .................................... 27

7.2 Cultivos nitrificantes en lote con ampicilina ............................ 29

7.3 Procesos de eliminación de ampicilina .............................. 35

7.3.1 Cinéticas de eliminación a $10 \mathrm{mg} / \mathrm{L}$ de ampicilina ................... 35

7.3.2 Cinéticas de eliminación a $25 \mathrm{mg} / \mathrm{L}$ de ampicilina ................... 37

7.3.3 Cinéticas de eliminación a $50 \mathrm{mg} / \mathrm{L}$ de ampicilina .................. 38

7.3.4 Resumen de procesos de eliminación de ampicilina ................. 38

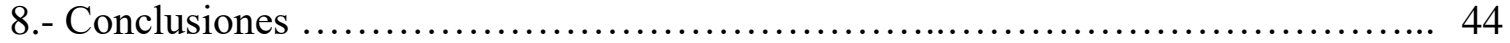

9.- Referencias ..................................................... 45 
Fig. 1. Consumo mundial de antibióticos por clase de 2000 a 2010. Unidad estándar se define como la dosis única (cápsula, comprimido o ámpula).

Grafica tomada de Van Boeckel et al., 2014.

Fig. 2. La molécula de penicilina y uno de los posibles derivados resultantes de la apertura del anillo betalactámico en medio acuoso ácido: $\mathrm{C}_{16} \mathrm{H}_{22} \mathrm{~N}_{3} \mathrm{O}_{5} \mathrm{~S}$. (tomado de Deshpande et al., 2004).

Fig. 3. Molécula de ampicilina, Nombre de la IUPAC: (2S, 5R, 6R)-6-[[(2R)-2amino-2-feniacetil] amino]-3,3-dimetil-7-oxo-4-thia-1-azabiciclo[3.2.0] heptano-2-ácido carboxílico. Fórmula: $\mathrm{C}_{16} \mathrm{H}_{19} \mathrm{~N}_{3} \mathrm{O}_{4} \mathrm{~S}$. Peso molecular de $349.40476 \mathrm{~g} / \mathrm{mol} . \mathrm{pKa}=2.5$ y $7.3,23{ }^{\circ} \mathrm{C}$ (https://pubchem.ncbi.nlm.nih.gov/ Compound/ampicillin\#section=Top)

Fig. 4. Ciclo de nitrógeno. Modificado de Atlas y Bartha, 2008 9

Fig. 5. Esquema del reactor nitrificante en continuo

Fig. 6. Curva de calibración de amonio empleando una membrana de ion selectivo de amoníaco.

Fig. 7. Curvas de calibración de nitrito y nitrato por cromatografía de líquidos (HPLC)

Fig. 8. Curvas de calibración de carbono total (CT) y carbono inorgánico (CI) ........ 24

Fig. 9. Curva de calibración de albúmina por espectrofotometría $\ldots \ldots \ldots \ldots \ldots \ldots \ldots . . \ldots 25$

Fig. 10. Curva de calibración de ampicilina por cromatografía de líquidos (HPLC) ..... 26

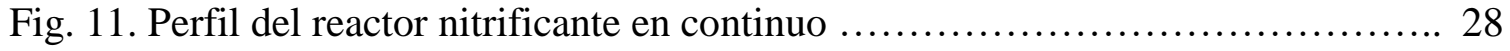

Fig. 12. Proceso nitrificante en cultivos en lote: (a) control sin ampicilina y (b) con $10 \mathrm{mg} / \mathrm{L}$ de ampicilina

Fig. 13. Proceso nitrificante en cultivos en lote: (a) control sin ampicilina y (b) con $25 \mathrm{mg} / \mathrm{L}$ de ampicilina. 30

Fig. 14. Proceso nitrificante en cultivos en lote: (a) control sin ampicilina y (b) con $50 \mathrm{mg} / \mathrm{L}$ de ampicilina

Fig. 15. Cinéticas de eliminación a $10 \mathrm{mg} / \mathrm{L}$ de ampicilina en ensayos abióticos, de adsorción y cultivos nitrificantes 
Fig. 16. Cinéticas de eliminación a $25 \mathrm{mg} / \mathrm{L}$ de ampicilina en ensayos abióticos, de adsorción y cultivos nitrificantes............................... 37

Fig. 17. Cinéticas de eliminación a $50 \mathrm{mg} / \mathrm{L}$ de ampicilina en ensayos abióticos, de adsorción y cultivos nitrificantes ................................ 38

Fig. 18. Contribución de los procesos abióticos, de adsorción y biotransformación en la eliminación de ampicilina en cultivos nitrificantes en lote 
Tabla 1. Composición del medio de cultivo para el reactor nitrificante en continuo ............................................................ 18

Tabla 2. Composición del medio de cultivo para los cultivos nitrificantes

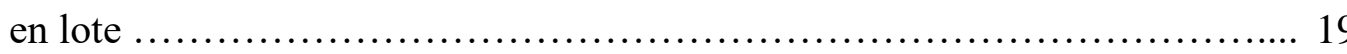

Tabla 3. Coeficientes de variación de las pendientes y de determinación correspondientes a las curvas de calibración realizadas con los diferentes métodos analíticos .......................................... 27

Tabla 4. Velocidades de carga y descarga en nitrógeno, eficiencia y rendimientos $^{*}(\mathrm{Y})$ del proceso nitrificante en el reactor continuo

Tabla 5. Ensayos sin y con ampicilina: eficiencias, rendimientos y velocidades específicas de la nitrificación en cultivos en lote

Tabla 6. Eliminación de ampicilina por procesos fisicoquímicos (abióticos), de adsorción en el lodo y biotransformación

Tabla 7. Eficiencias y velocidades específicas de eliminación de ampicilina en cultivos en lote

Tabla 8. Concentración de oxígeno disuelto (OD) y ampicilina en un cultivo nitrificante con $25 \mathrm{mg} / \mathrm{L}$ de ampicilina 


\section{Resumen}

Los contaminantes orgánicos emergentes (EOC: emerging organic contaminants) comprenden un amplio conjunto de compuestos en los que se incluyen metabolitos y productos de transformación, presentes en el ambiente en cantidades de ng a mg. Dentro de los EOC, se encuentran fármacos, productos de cuidado personal, pesticidas, etc. Más de la mitad de los antibióticos producidos mundialmente son betalactámicos y muchos de ellos se han detectado en los efluentes de las plantas de tratamiento de aguas residuales, entre ellos la ampicilina. La presencia de antibióticos en el medio acuático es preocupante ya que pueden contribuir a la resistencia bacteriana, y además se desconoce el efecto sinérgico que puede haber con otros contaminantes presentes en el medio sobre la salud humana y los ecosistemas. La contaminación del agua por nitrógeno se da principalmente por la presencia de amonio en aguas residuales y su eliminación en las plantas de tratamiento se lleva a cabo a través de procesos biológicos como la nitrificación y la desnitrificación. Los estudios sobre la biotransformación de la ampicilina por lodos nitrificantes y el efecto de este antibiótico sobre la nitrificación son escasos. El objetivo de este trabajo fue evaluar la capacidad de un cultivo nitrificante para la biotransformación de amonio y ampicilina en cultivos en lote, así como evaluar el efecto de este antibiótico sobre el proceso nitrificante. Se realizó el estudio del comportamiento fisiológico y cinético del consorcio nitrificante en presencia de ampicilina (10, 25 y $50 \mathrm{mg} / \mathrm{L})$ usando variables de respuesta como eficiencias de consumo, rendimientos y velocidades específicas.

Como fuente de inóculo para los cultivos en lote, se empleó un reactor en continuo de tanque agitado con lodo nitrificante, fisiológicamente estable $\left(\mathrm{E}_{\mathrm{NH} 4+}(\%)\right.$ de $99.9 \pm 0.1 ; \mathrm{Y}$ ( $\mathrm{mg} \mathrm{N} / \mathrm{mg} \mathrm{N}-\mathrm{NH}_{4}{ }^{+}$consumido) de nitrato: $0.77 \pm 0.06$; de nitrito: $0.02 \pm 0.02$ y de biomasa microbiana: $0.04 \pm 0.01$ ). Bajo las condiciones experimentales y a las concentraciones de ampicilina de 10, 25 y $50 \mathrm{mg} / \mathrm{L}$, no se observó efecto alguno sobre la eficiencia $(\mathrm{E}=99.7 \pm$ $4.2 \%)$ y los rendimientos $\left(\mathrm{YNO}_{2}{ }^{-}=0, \mathrm{YNO}_{3}{ }^{-}=1.0 \pm 0.1 \mathrm{mg} \mathrm{N} / \mathrm{mg} \mathrm{N}-\mathrm{NH}_{4}{ }^{+}\right.$consumido) del proceso nitrificante, comportándose el lodo en los controles sin ampicilina y los ensayos con antibiótico de forma muy similar. Al igual que el comportamiento fisiológico del consorcio, la cinética de la respiración nitrificante tampoco sufrió cambios significativos en presencia de ampicilina. Las velocidades específicas tanto de oxidación de amonio como de 
formación de nitrato fueron similares entre los cultivos control y los cultivos con antibiótico, mostrando que la ampicilina tampoco provocó un efecto inhibitorio en la nitrificación. En conjunto los resultados obtenidos de eficiencias, rendimientos y velocidades específicas aportan evidencias claras de que la ampicilina hasta $50 \mathrm{mg} / \mathrm{L}$ no afectó ni la fisiología ni la cinética del proceso respiratorio nitrificante. La eliminación de ampicilina en los cultivos se dio principalmente a través de los procesos de biosorción (adsorción en el lodo) (23.2 a 47.0\%) y de biotransformación (10.0 a 29.8\%) y en menor medida a través de procesos físico-químicos (16.0 a 16.5\%). A las tres concentraciones iniciales de ampicilina adicionada, se observó un remanente de antibiótico después de $24 \mathrm{~h}$ de cultivo (26.9 a $34.1 \%$ ), obteniéndose una eficiencia promedio de $70.5 \pm 2.5 \%$. Despues de $94 \mathrm{~h}$ de cultivo, el antibiótico $(25 \mathrm{mg} / \mathrm{L})$ pudo ser eliminado hasta un $79.3 \%$. El bajo consumo de ampicilina después de $24 \mathrm{~h}$ pudo probablemente estar relacionado con una limitación de oxígeno disuelto $(2.0 \pm 0.1 \mathrm{mg} \mathrm{OD} / \mathrm{L}) \mathrm{y} / \mathrm{o}$ el valor de $\mathrm{pH}$ de 5.8. Con el incremento en la concentración inicial de antibiótico, hubo una mayor participación del lodo en el proceso de biotransformación de la ampicilina y a la vez un aumento en la velocidad específica de consumo. Estos resultados muestran que el lodo fue capaz de oxidar amonio a nitrato por nitrificación y eliminar ampicilina por vía biológica. El lodo nitrificante mostró capacidad de transformar la ampicilina, pero sin llegar a la mineralización completa. Dado que no se observó alteración alguna del proceso nitrificante en presencia de ampicilina, se pudo descartar la participación de las bacterias nitrificantes en la biotransformación de la ampicilina y sugerir la participación de la microflora heterótrofa del consorcio. 


\section{Abstract}

The emerging organic contaminants (EOCs) comprise a broad set of compounds that include metabolites and transformation products, present in the environment in amounts of ng to mg. Within the EOCs, there are drugs, personal care products, pesticides, etc. More than half of the antibiotics produced worldwide are beta-lactams and many of them have been detected in effluents from sewage treatment plants, including ampicillin. The presence of antibiotics in the aquatic environment is of concern and may contribute to bacterial resistance, and also the synergistic effect that may exist with other pollutants present in the environment on human health and ecosystems is unknown. The pollution of water by nitrogen is mainly due to the presence of ammonium in wastewater, and its elimination in treatment plants is mainly carried out through biological processes such as nitrification and denitrification. Studies on the biotransformation of ampicillin by nitrifying sludge and the effect of this antibiotic on nitrification are scarce. The objective of this work was to evaluate the capacity of a nitrifying culture for the biotransformation of ammonium and ampicillin in batch cultures, as well as to evaluate the effect of this antibiotic on the nitrifying process. The study of the physiological and kinetic behavior of the nitrifying consortium in the presence of ampicillin (10, 25 and $50 \mathrm{mg} / \mathrm{L})$ was carried out using response variables such as consumption efficiencies, yields and specific rates.

As a source of inoculum for batch cultures, a continuous stirred tank reactor with nitrifying sludge, physiologically stable was used $\left(\mathrm{E}_{\mathrm{NH} 4+}(\%)\right.$ de $99.9 \pm 0.1 ; \mathrm{Y}\left(\mathrm{mg} \mathrm{N} / \mathrm{mg} \mathrm{NH}_{4}{ }^{+}-\mathrm{N}\right.$ consumed) nitrate: $0.77 \pm 0.06$; nitrite: $0.02 \pm 0.02$ and microbial biomass: $0.04 \pm 0.01$ ). Under the experimental conditions and ampicillin concentrations of 10,25 and $50 \mathrm{mg} / \mathrm{L}$, no effect on efficiency $(\mathrm{E}=99.7 \pm 4.2 \%)$ and yields $\left(\mathrm{YNO}_{2}{ }^{-}=0, \mathrm{YNO}_{3}{ }^{-}=1.0 \pm 0.1 \mathrm{mg} \mathrm{N} / \mathrm{mg}\right.$ $\mathrm{N}-\mathrm{NH}_{4}{ }^{+}$consumed) of the nitrifying process was observed as the sludge behavior was very similar in the controls without ampicillin and the assays with antibiotic. Like the physiological behavior of the consortium, the kinetics of nitrifying respiration also did not have significant changes in the presence of ampicillin. The specific rates of both ammonium oxidation and nitrate formation were similar between control cultures and cultures with antibiotic, showing that ampicillin did not cause an inhibitory effect on nitrification either. Overall, the results obtained from efficiencies, yields and specific rates 
provide clear evidence that ampicillin up to $50 \mathrm{mg} / \mathrm{L}$ did not affect the physiology or kinetics of the nitrifying respiratory process.

The elimination of ampicillin in the cultures was mainly attributed to the processes of biosorption (adsorption on the sludge) (23.2 to 47.0\%) and biotransformation (10.0 to $29.8 \%$ ) and to a lesser extent to physical-chemical processes (16.0 to $16.5 \%)$. At the three initial concentrations of ampicillin added, a remnant of antibiotic was observed after $24 \mathrm{~h}$ of culture (26.9 to $34.1 \%$ ), obtaining an average efficiency of $70.5 \pm 2.5 \%$. After $94 \mathrm{~h}$ of culture, the antibiotic $(25 \mathrm{mg} / \mathrm{L})$ could be eliminated up to $79.3 \%$. The low consumption of ampicillin after $24 \mathrm{~h}$ could probably be related to a limitation of dissolved oxygen $(2.0 \pm$ $0.1 \mathrm{mg} \mathrm{DO} / \mathrm{L}$ ) and/or the $\mathrm{pH}$ value of 5.8. With the increase in the initial concentration of antibiotic, there was a greater participation of the sludge in the biotransformation process of ampicillin and at the same time an increase in the specific rate of ampicillin consumption. These results show that the sludge was able to oxidize ammonium to nitrate by nitrification and eliminate ampicillin biologically. The nitrifying sludge showed the ability to transform ampicillin, but without reaching full mineralization. Given that no alteration of the nitrifying process was observed in the presence of ampicillin, it is possible to rule out the participation of nitrifying bacteria in the biotransformation of ampicillin and to suggest the participation of the consortium's heterotrophic microflora. 
1.- Introducción

\subsection{Contaminantes orgánicos emergentes (EOC)}

Los contaminantes orgánicos emergentes (EOC: emerging organic contaminants) comprenden un amplio conjunto de compuestos diferentes, tales como metabolitos y productos de transformación, presentes en el ambiente en cantidades de ng a mg. Dentro de los EOC, se incluyen a fármacos, productos de cuidado personal, pesticidas, productos veterinarios, compuestos o subproductos industriales, aditivos, nanomateriales, entre otros (Lapworth et al., 2012; Petrie et al., 2015).

Estos EOC aparecen en el ambiente a consecuencia de su creación, uso y liberación al entorno. Al estar presentes en diversos medios acuáticos y terrestres se puede decir que los EOC son omnipresentes (Petrie et al., 2015). Los EOC en el ambiente son, o pueden ser, potencialmente tóxicos ya sea para el humano o para otras especies. Su presencia en los ecosistemas en concentraciones determinadas como inocuas, es motivo de preocupación creciente ya que normalmente no aparecen de forma individual, sino que se presentan como una mezcla compleja que puede dar lugar a efectos sinérgicos indeseables (y muchas veces desconocidos) sobre los organismos expuestos a ellos de forma continua (Lapworth et al., 2012; Meffe y de Bustamante, 2014; Petrie et al., 2015).

En el caso del ambiente acuático las vías de ingreso de estos contaminantes al entorno son a través por ejemplo, de los efluentes de las plantas de tratamiento de aguas, efluentes de hospitales, derivados de actividades ganaderas, aplicación de estiércol a terrenos agrícolas, relleno sanitario, desechos industriales, etc. (Lapworth et al., 2012; Stuart et al., 2012; Petrie et al., 2015).

La biodegradación es frecuentemente la vía dominante para la remoción de algunos EOC de la fase acuosa de las aguas de desecho así como de las aguas superficiales, sin embargo, esto puede resultar en la formación de numerosos productos de degradación o transformación más tóxicos que el compuesto de origen (Petrie et al., 2015).

El proceso convencional de tratamiento de aguas de desecho a través de lodos activados y filtración, no es adecuado para eliminar completamente los EOC, lo que resulta finalmente en su descarga en aguas superficiales (Petrie et al., 2015). Las aguas superficiales presentan de hecho la mayor carga de EOC (Lapworth et al., 2012). Las plantas de 
tratamiento de aguas de desecho pueden eliminar estos contaminantes en cantidades variables, esta variación se debe por ejemplo a que los EOC tienen diferentes propiedades fisicoquímicas, una susceptibilidad distinta a la biodegradación, o a condiciones de operación en los sistemas de tratamiento. Si bien estos contaminantes se pueden reducir en cantidades importantes, siguen presentes en los efluentes de plantas de tratamiento (Petrie et al., 2015) y aún constituyen o pueden constituir un riesgo ambiental y de salud (Heberer, 2001; Pal et al., 2010; Mutiyar y Mittal, 2014). Por ejemplo, se han encontrado residuos contaminantes farmacéuticos en efluentes de plantas de tratamiento municipales de Berlín, y también en canales, lagos y ríos donde se descargaron esas aguas tratadas, así como en agua de llave (dependiendo de la metodología empleada para la purificación) a nivel de ng/L (Heberer, 2001). Las concentraciones mencionadas pudieran parecer insignificantes, pero hay que tener presente que además del efecto sinérgico que puede presentarse, algunos EOC como las hormonas, tienen la capacidad de actuar directamente a concentraciones muy bajas y su efecto adverso en los ecosistemas puede ser importante. Al respecto cabe mencionar que la exposición de peces a 5-6 ng/L de 17 $\alpha$-etinilestradiol (estrógeno sintético, componente de anticonceptivos) puede resultar en la feminización de peces macho y el eventual colapso de la población (Heberer, 2001; Kidd et al., 2007; Pal et al., 2010). En efluentes de plantas de tratamiento, las hormonas se han detectado en concentraciones menores a $100 \mathrm{ng} / \mathrm{L}$ (Pal et al., 2010).

La falta de información y regulación de los EOC también deriva en una subestimación de estos contaminantes en influentes y efluentes de las plantas de tratamiento, lo que resulta en un escaso conocimiento de su destino, y el efecto que pueden tener sobre los organismos acuáticos o terrestres expuestos a ellos (Pal et al., 2010; Lapworth et al., 2012). En el caso de los lodos, éstos pueden actuar como un medio de concentración de los EOC por adsorción, es decir que no se resuelve el problema de su eliminación sino que se traslada el contaminante del agua a otro medio (Lapworth et al., 2012; Petrie et al., 2015).

\subsection{Los antibióticos}

El descubrimiento de los antibióticos es uno de los hechos más importantes en la medicina moderna y ha contribuido a la reducción mundial de enfermedades infecciosas tanto en 
humanos como en animales (Laxminarayan et al., 2015). Se ha estimado que la cantidad total de antibióticos consumida mundialmente es de 100000 a 200000 toneladas por año (Kümmerer, 2009a). Después de su administración, estos compuestos son desechados y transportados al medio ambiente a través de aguas residuales industriales, de hospitales, descargas derivadas de granjas y efluentes domésticos. De la dosis de antibiótico utilizada, 30 a 90\% (dependiendo del antibiótico) se presenta en efluentes en la forma original activa, es decir sin haber sufrido transformación alguna (Birošová et al., 2014). Una vez en el medio ambiente, los residuos de antibióticos pueden constituir un riesgo para las redes tróficas, incluso alterar la capacidad del suelo para descomponerlos, tener efectos sobre los organismos acuáticos y promover el desarrollo de bacterias con genes de resistencia. Las aguas residuales urbanas al contener excretas de humanos y animales representan los reservorios más importantes de resistencia ya que coexisten tanto sustancias antimicrobianas como bacterias comensales o patógenas resistentes, entre otros microorganismos (Kümmerer, 2009b; Chen et al., 2014; Chen y Zhou, 2014). Es importante señalar que muchos antimicrobianos que normalmente se usan en medicina humana también tienen un uso veterinario. Esto incrementa la carga de residuos de estos compuestos que se presentan en el medio ambiente así como la posibilidad de aparición de microorganismos resistentes (Kümmerer, 2009b; Rosenblatt-Farrell, 2009). Los antimicrobianos son aplicados a animales por una variedad de razones que incluyen el tratamiento de enfermedades, su prevención, su control, así como promotores de crecimiento (Marshall y Levy, 2011). El consumo mundial de antimicrobianos relacionados con la producción de animales de granja en 2010 fue de alrededor de 63151 toneladas y se espera que en 2030 alcance aproximadamente las 105596 toneladas (Laxminarayan et al., 2015).

En general, los antibióticos son resistentes a la biodegradación y persistentes (o pseudopersistentes debido a que se producen en grandes cantidades y se vierten continuamente), acumulándose en el ambiente y siendo capaces de provocar efectos dañinos en los ecosistemas. Los tratamientos de aguas convencionalmente empleados: coagulación, floculación, sedimentación, filtración y tratamiento biológico no eliminan totalmente estos compuestos y como resultado aparecen en los efluentes de las plantas de tratamiento y cuerpos de agua naturales (Homem y Santos, 2011; Birošová et al., 2014). 
Las aguas de desecho de la industria con estos contaminantes se pueden tratar empleando procesos físicos y químicos, como son los procesos foto catalíticos con $\mathrm{UV} / \mathrm{ZnO}$, proceso foto-Fenton, procesos ultrasónicos, procesos de oxidación avanzada y adsorción. Estos métodos no son comúnmente empleados debido a su complejidad, altos costos de operación y en la mayoría de los casos por ser imprácticos de emplearse en modo continuo. La adsorción es otro proceso alternativo a las técnicas de oxidación y muy eficiente (eliminación arriba del 80\%), sin embargo tiene la desventaja de producir un nuevo residuo así como el costo del material adsorbente (Homem y Santos, 2011; Ahmed et al., 2015). La combinación de tratamientos físicos, químicos y biológicos sería el tratamiento más eficiente en la eliminación de antibióticos (Homem y Santos, 2011; Michael et al., 2013). En general, el tratamiento biológico es ampliamente utilizado debido a su bajo costo, manejo de altas tasas de flujo, y adecuado para el tratamiento de aguas residuales con una alta demanda química de oxígeno (DQO). El tratamiento biológico continúa siendo una buena opción para el tratamiento de aguas contaminadas con antibióticos, en adición de los procesos físico-químicos previamente mencionados (Homem y Santos, 2011; Michael et al., 2013).

\subsubsection{Los betalactámicos}

Los betalactámicos (o $\beta$-lactámicos) son la clase de antibióticos más extensamente usada en la práctica clínica, con una acción bactericida lenta y dependiente del tiempo, cuyo mecanismo de acción es la inhibición de la última etapa de la síntesis de la pared bacteriana (Suárez y Gudiol, 2009). Los betalactámicos representan más de la mitad del mercado mundial de antibióticos (Fig. 1) (Kümmerer, 2009a; Suárez y Gudiol, 2009; Van Boeckel et al., 2014). 


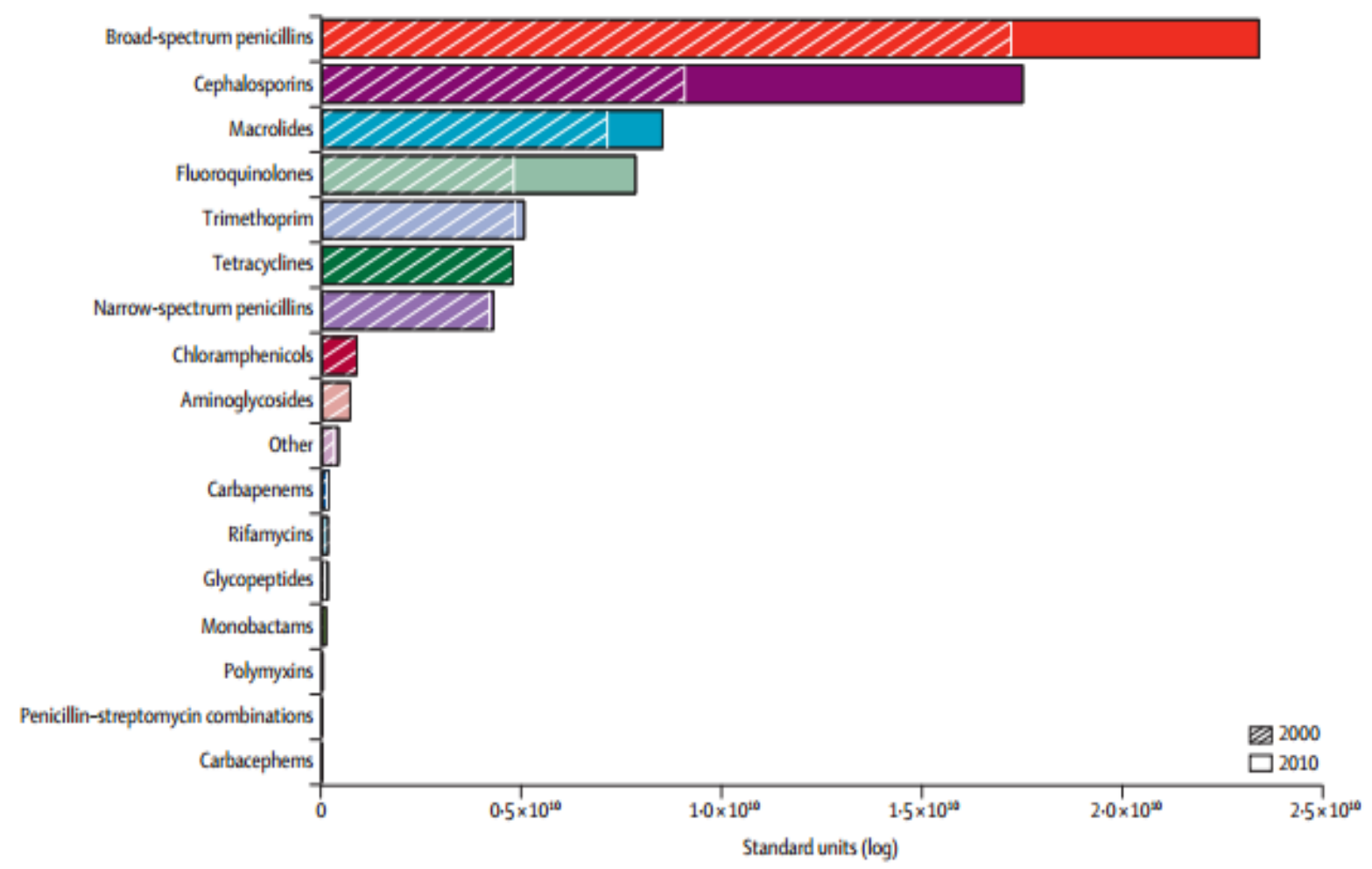

Figura 1. Consumo mundial de antibióticos por clase de 2000 a 2010. Unidad estándar se define como una dosis única (cápsula, comprimido o ámpula). Grafica tomada de Van Boeckel et al., 2014.

Los betalactámicos se caracterizan por tener un anillo de tres carbonos y un nitrógeno, el cual se une a otro secundario, formando ambos el núcleo betalactámico. Dependiendo de las cadenas adicionales al anillo betalactámico que se presenten, así como de la molécula que actúe como anillo secundario será el grupo al que pertenezca un compuesto betalactámico. Así dentro de la clase de los betalactámicos está el grupo de las penicilinas, formadas por un anillo betalactámico unido a un anillo de tiazolidina (formando ambos el núcleo betalactámico ácido 6-aminopenicilánico), con el anillo betalactámico unido a una cadena lateral (Oshiro, 1999; Suárez y Gudiol, 2009; Homem y Santos, 2011).

La propiedad antibacterial de la penicilina se debe a la fusión del anillo betalactámico con el anillo tiazolidínico, sin embargo esta unión conduce a un sistema bicíclico tensionado que es susceptible de romperse en algún punto bajo acción de múltiples especies químicas tales como nucleófilos, ácidos y bases, iones metálicos, agentes oxidantes, enzimas e incluso agua y alcoholes entre otros solventes (Fig. 2). Para dar mayor actividad y estabilidad a la penicilina se crearon derivados como la ampicilina y la amoxicilina (ambos compuestos con un amplio espectro de acción), entre muchos otros (Deshpande et al., 
2004). Las aminopenicilinas son generalmente estables en estado sólido, pero en solución son estables sólo por tiempos cortos, como otras penicilinas, son a su vez dependientes del pH y de la temperatura. Las aminopenicilinas son más resistentes a la hidrólisis por ácidos por lo que son generalmente estables en presencia de secreciones gástricas (https://pubchem.ncbi.nlm.nih.gov/ compound/ampicillin\#section=Top).

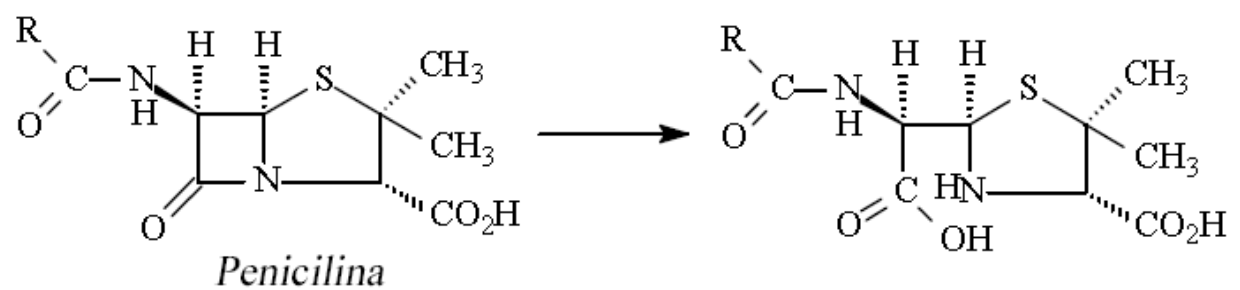

Ácido peniciloico

Figura 2. La molécula de penicilina y uno de los posibles derivados resultantes de la apertura del anillo betalactámico en medio acuoso ácido: $\mathrm{C}_{16} \mathrm{H}_{22} \mathrm{~N}_{3} \mathrm{O}_{5} \mathrm{~S}$. (tomado de Deshpande et al., 2004)

Los betalactámicos son eliminados de manera significativa durante el tratamiento biológico de aguas residuales, en un porcentaje variable, dependiendo del antibiótico que se trate (Watkinson et al., 2009; Zuccato et al., 2010; Michael et al., 2013).

\subsubsection{La ampicilina}

La ampicilina es una amino penicilina y es equivalente a su sucesor la amoxicilina en términos de semejanza molecular así como en su espectro de acción y nivel de actividad (Fig. 3). Es un antibiótico semisintético, de amplio espectro y activo por vía oral. La ampicilina, y en general los antibióticos $\beta$-lactámicos, actúan inhibiendo la última etapa de la síntesis de la pared bacteriana al unirse a proteínas específicas llamadas PBP (Penicillin Binding Proteins) localizadas en la pared celular, ocasionando la lisis de la bacteria. En general, los $\beta$-lactámicos debido a su carácter hidrofílico (ampicilina Kow=0.079, tomado de https://pubchem.ncbi.nlm.nih.gov/ compound/6249) no penetran fácilmente la membrana plasmática, por lo que no son útiles en el tratamiento de infecciones 
intracelulares (Suárez y Gudiol, 2009). La ampicilina, y la amoxicilina, son los fármacos preferidos en el tratamiento de infecciones urinarias (Oshiro, 1999; Suárez y Gudiol, 2009). La ampicilina se puede administrar oral y parenteralmente y es eliminada del cuerpo sin cambio alguno casi en su totalidad a través de orina y contenido intestinal (Acred et al., 1962). La ampicilina en solución, se hidroliza a pH 7 y $25^{\circ} \mathrm{C}$ con vida media de 27 d, pero a pH 7 y $50{ }^{\circ} \mathrm{C}$ es de $1.2 \mathrm{~d}$, es decir que es sensible a la temperatura. Es más lábil a pH básico que en medio ácido $(\mathrm{pH}<4)$ (Mitchel et al., 2014). La ampicilina es estable a la luz (Naveed et al., 2014) y resistente a la acción hidrolítica de muchas $\beta$-lactamasas (https://pubchem. ncbi.nlm.nih.gov/compound/ ampicillin\#section=Top).

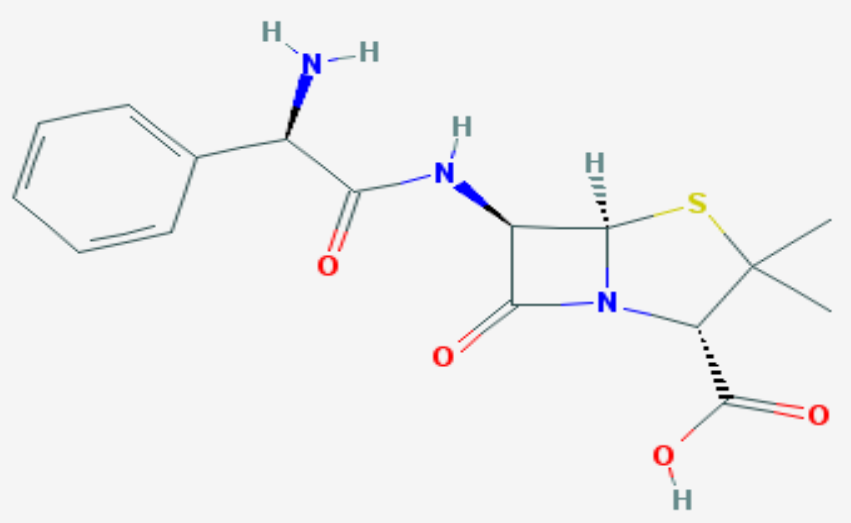

Figura 3. Molécula de ampicilina, Nombre de la IUPAC: (2S, 5R, 6R)-6-[[(2R)-2-amino-2feniacetil]amino]-3,3-dimetil-7-oxo-4-thia-1-azabiciclo[3.2.0]heptano-2-ácido carboxílico. Fórmula: $\mathrm{C}_{16} \mathrm{H}_{19} \mathrm{~N}_{3} \mathrm{O}_{4} \mathrm{~S}$. Peso molecular de $349.40476 \mathrm{~g} / \mathrm{mol}$. pKa $=2.5$ y 7.3, $23{ }^{\circ} \mathrm{C}$. (https://pubchem.ncbi.nlm.nih.gov/compound/ampicillin\#section=Top)

En el caso de la ampicilina, se ha detectado en influentes de plantas de tratamiento (India) en concentración de $104.2 \pm 98.11 \mu \mathrm{g} / \mathrm{L}$ y en sus efluentes de $12.68 \pm 8.38 \mu \mathrm{g} / \mathrm{L}$ (Mutiyar y Mittal, 2014). En el efluente de una compañía farmacéutica (China), se encontró $3.5 \mathrm{mg} / \mathrm{L}$ de ampicilina (Zhou et al., 2006). Este antibiótico ha sido eliminado en un $82 \%$ en un proceso de lodos activados, y una eliminación mayor al $94 \%$ se ha conseguido con un tratamiento en un biorreactor de membrana (MBR, Membrane bioreactor) con un tiempo de retención celular de 3 a 60 días (Michael et al., 2013). En experimentos con partículas de carbón activado recubiertas de una biopelícula en un reactor airlift, tras la adición de 
ampicilina en concentraciones de 4 y $8 \mathrm{mg} / \mathrm{L}$, durante 40 días de operación no se detectó ampicilina en el efluente. En este estudio, si bien el proceso de adsorción fue el predominante, la biodegradación llegó a ser importante conforme se desarrolló la biopelícula sobre las partículas de carbón activado (Shen et al., 2011).

\subsection{Eliminación de contaminantes por procesos biológicos}

La contaminación del agua por carbono, nitrógeno, azufre, fósforo, contaminantes emergentes, entre otros compuestos, es un grave problema ambiental. Algunas aguas residuales como los efluentes de la industria química y petroquímica constituyen un reto en su tratamiento debido a su complejidad química, y la eliminación de todos o algunos de estos compuestos a través de un proceso microbiológico es una contribución importante en la detoxificación de las aguas residuales y suelos contaminados así como para los principales ciclos biogeoquímicos (Atlas y Bartha, 2008; Conley et al., 2009).

\subsubsection{El ciclo del nitrógeno}

El ciclo del nitrógeno es uno de los ciclos biogeoquímicos que han sido afectados por las actividades humanas de una manera drástica en los últimos 50 años. El nitrógeno molecular $\left(\mathrm{N}_{2}\right)$ que se encuentra en la atmósfera, constituye un enorme depósito de este elemento (3.8 x $10^{15}$ t) junto con las rocas ígneas y las sedimentarias donde se presenta el nitrógeno en forma de amonio fijo, no disponible directamente (Atlas y Bartha, 2008). El ciclo del nitrógeno (Fig. 4) se compone de seis grandes procesos con participación microbiana: la fijación de nitrógeno, la reducción desasimilatoria del nitrato a amoniaco, la amonificación, la oxidación anaerobia de amonio (anammox), la nitrificación y la desnitrificación.

Una concentración demasiado alta de nitrógeno en los cuerpos de aguas puede conducir a la eutrofización, la hipoxia, la pérdida del hábitat y de la biodiversidad (Conley et al., 2009). La nitrificación y la desnitrificación son los principales procesos biológicos que se usan en la eliminación del nitrógeno de las aguas residuales. La oxidación de amonio y nitrito juega un papel clave en la generación de una fuente de nitrato para las bacterias desnitrificantes. El acoplamiento del proceso de nitrificación (que requiere oxígeno) con el proceso de 
desnitrificación (anóxico) conduce a la liberación de nitrógeno molecular a la atmósfera. La nitrificación es un proceso respiratorio aerobio realizado principalmente por dos grupos de bacterias Gram negativas, quimiolitoautótrofas y filogenéticamente no relacionadas entre sí, las amonio oxidantes y las bacterias nitrito oxidantes, ambas pertenecientes a la familia Nitrobacteraceae. La desnitrificación es la reducción de compuestos nitrogenados oxidados como nitrato y nitrito a nitrógeno molecular. Este proceso biológico es llevado a cabo por bacterias quimioorganótrofas, litoautótrofas y fotótrofas, así como hongos (Atlas y Bartha, 2008).

\section{Ciclo del Nitrógeno}

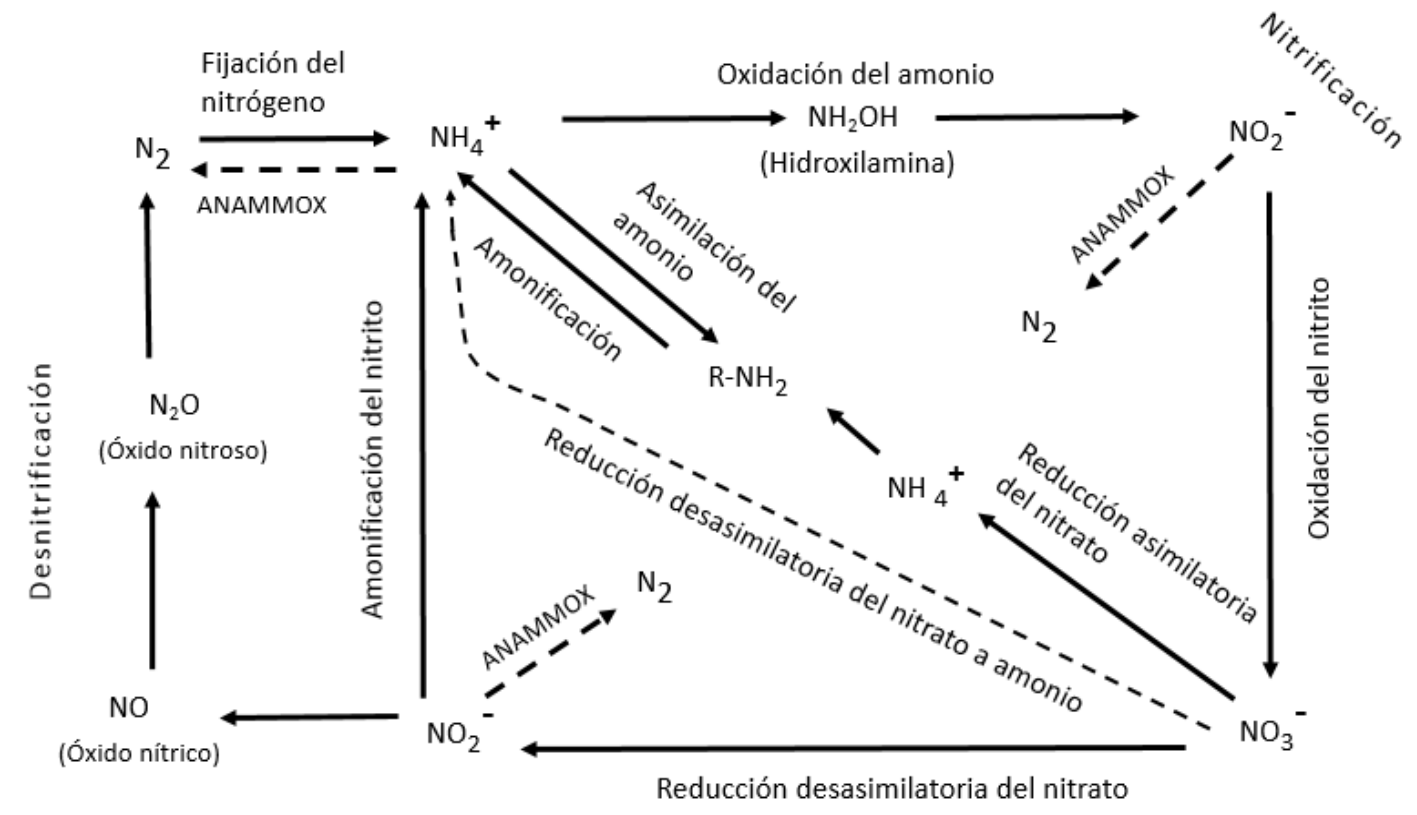

Figura 4. Ciclo de nitrógeno. Modificado de Atlas y Bartha, 2008.

\subsubsection{Amonio oxidación}

Las bacterias amonio oxidantes (AOB) son especies de los siguientes géneros: Nitrosomonas, Nitrosospira, Nitrosolobus, Nitrosococcus y Nitrosovibrio, siendo Nitrosomonas el género más estudiado (Beristain-Cardoso et al., 2009). 
Las proteobacterias amonio oxidantes obtienen energía de la oxidación aerobia de este sustrato. En un primer paso la enzima amonio monooxigenasa (AMO) cataliza la oxidación de amonio a hidroxilamina $\left(\mathrm{NH}_{2} \mathrm{OH}\right)$ (ecuación 1):

$$
\mathrm{NH}_{4}{ }^{+}+0.5 \mathrm{O}_{2} \rightarrow \mathrm{NH}_{2} \mathrm{OH}+\mathrm{H}^{+}\left(\Delta \mathrm{G}^{\mathrm{O}^{\prime}}=-8.2 \mathrm{~kJ} / \text { reacción }\right)
$$

La hidroxilamina resultante finalmente se oxida a nitrito por acción de la enzima hidroxilamina oxidorreductasa (HAO) (ecuación 2):

$$
\mathrm{NH}_{2} \mathrm{OH}+\mathrm{O}_{2} \rightarrow \mathrm{NO}_{2}{ }^{-}+\mathrm{H}^{+}+\mathrm{H}_{2} \mathrm{O} \quad\left(\Delta \mathrm{G}^{\mathrm{O}^{\prime}}=-266.5 \mathrm{~kJ} / \text { reacción }\right)
$$

En resumen, el amonio es empleado como donador de electrones y el aceptor final es el oxígeno, con la siguiente reacción (ecuación 3) (Beristain-Cardoso et al., 2009; Bernet y Spérandio, 2009):

$$
\mathrm{NH}_{4}{ }^{+}+1.5 \mathrm{O}_{2} \rightarrow \mathrm{NO}_{2}{ }^{-}+2 \mathrm{H}^{+}+\mathrm{H}_{2} \mathrm{O} \quad\left(\Delta \mathrm{G}^{\mathrm{O}^{\prime}}=-274.7 \mathrm{~kJ} / \text { reacción }\right)
$$

Comparando la energía liberada en estas reacciones se observa que es a través de la oxidación de hidroxilamina a nitrito (ecuación 2) que las AOB obtienen la mayor parte de su energía, sin embargo el valor es bajo lo que indica que el ATP producido también es escaso y como consecuencia de esto el crecimiento de las AOB es también bajo. Esto concuerda con los tiempos de duplicación de 7 a 24 h que se han registrado para este grupo de bacterias (Beristain-Cardoso et al., 2009).

Otros productos que son capaces de generar las AOB a partir de amonio y nitrito (en concentraciones de oxígeno menores a $0.8 \mathrm{mg} / \mathrm{L}$ ) son óxido nítrico (NO), óxido nitroso $\left(\mathrm{N}_{2} \mathrm{O}\right)$ y $\mathrm{N}_{2}$, empleando una parte del nitrito producido como aceptor final de electrones (Schmidt et al., 2003).

\subsubsection{Nitrito oxidación}

En el caso de las bacterias oxidantes del nitrito (NOB), se tienen como géneros 
representativos a Nitrobacter, Nitrospina, Nitrococcus y Nitrospira, siendo Nitrobacter el género mejor estudiado. En esta etapa, el nitrito se oxida a nitrato, y la reacción es catalizada por el complejo enzimático nitrito oxidorreductasa (NOR) (ecuación 4) (Atlas y Bartha, 2008; Beristain-Cardoso et al., 2009):

$$
\mathrm{NO}_{2}{ }^{-}+0.5 \mathrm{O}_{2} \rightarrow \mathrm{NO}_{3}{ }^{-}\left(\Delta \mathrm{G}^{\mathrm{O}^{\prime}}=-74.1 \mathrm{~kJ} / \text { reacción }\right)
$$

El valor del cambio de energía libre para la oxidación del nitrito a nitrato es aún más bajo que en la oxidación del amonio a nitrito, lo que limitará el crecimiento de las NOB. Los tiempos de duplicación para las NOB son de 10 a 40 h, es decir aún mayores que para las bacterias amonio oxidantes (Beristain-Cardoso et al., 2009; Bernet y Spérandio, 2009).

Se presenta a continuación la ecuación general de la nitrificación que incluye el crecimiento celular (ecuación 5):

$$
\mathrm{NH}_{4}{ }^{+}+1.83 \mathrm{O}_{2}+1.98 \mathrm{HCO}_{3}{ }^{-} \rightarrow 0.021 \mathrm{C}_{5} \mathrm{H}_{7} \mathrm{O}_{2} \mathrm{~N}+0.98 \mathrm{NO}_{3}{ }^{-}+1.041 \mathrm{H}_{2} \mathrm{O}+1.88 \mathrm{H}_{2} \mathrm{CO}_{3}
$$

Se puede estimar que son necesarios $7.6 \mathrm{mg}$ de amonio por cada $\mathrm{mg}$ de biomasa formada, o visto de otra manera se formarán $0.132 \mathrm{mg}$ de biomasa/mg de amonio (Bernet y Spérandio, 2009).

\subsubsection{Consorcios nitrificantes}

Un aspecto interesante de la nitrificación es que consorcios microbianos bajo condiciones nitrificantes son capaces de oxidar simultáneamente amonio y compuestos orgánicos (Sayavedra-Soto et al., 2010). Estudios con Nitrosomonas europaea han mostrado que la enzima AMO está involucrada en la oxidación de un amplio rango de hidrocarburos, incluyendo compuestos aromáticos (Beristain-Cardoso et al., 2009; Sayavedra-Soto et al., 2010). La biodegradación es conocida como el proceso de conversión de compuestos de gran peso molecular a otros de menor complejidad empleando microorganismos. En el caso de compuestos orgánicos, éstos pueden ser convertidos a moléculas simples inorgánicas tales como agua y dióxido de carbono. En el proceso convencional de biodegradación, los 
microorganismos usan los compuestos como sustratos primarios (fuente de carbono y energía) para su crecimiento celular y se inducen las enzimas para su asimilación. El cometabolismo se define como la transformación de un sustrato que no está destinado al crecimiento en presencia obligada de un sustrato usado para crecer u otro compuesto biodegradable (Tran et al., 2013). Algunos estudios sugieren que el cometabolismo permite iniciar una reacción a fin de convertir compuestos persistentes a sus intermediarios que pueden ser más biodegradables y participar en las principales rutas metabólicas para su posterior biotransformación. Un proceso natural que puede incluir la biodegradación de los EOC por cometabolismo es la nitrificación (Beristain-Cardoso et al., 2009; Sayavedra-Soto et al., 2010; Tran et al., 2013). Como muchas monooxigenasas, la AMO tiene un amplio rango de sustratos (más de 40) y es capaz de oxidar contaminantes orgánicos entre los que se incluyen: alcanos (hasta $\mathrm{C}_{8}$ ), alquenos (hasta $\mathrm{C}_{5}$ ), hidrocarburos halogenados, benceno, fenol, ciclohexano (McCarty, 1999; Khunjar et al., 2011; Sayavedra-Soto et al., 2010; Silva et al., 2011b; Tran et al., 2013) y también fármacos (EOC) como: diclofenaco, naproxeno, carbamazepina, propifenazona (Tran et al., 2009), trimetoprima (Batt et al., 2006) y $17 \alpha-$ etinilestradiol (Khunjar et al., 2011). A fin de evaluar la participación de la AMO en la biodegradación de los EOC, se ha empleado aliltiourea (ATU), que es un inhibidor específico de la AMO y suprime la actividad amonio oxidante. Si el compuesto blanco se biodegrada, aún en presencia de ATU, esto implica que la biodegradación llevada a cabo es debida a procesos donde no participa la AMO (Tran et al., 2009; Khunjar et al., 2011; Silva Luna, 2011). En consorcios nitrificantes, los autótrofos oxidantes del amonio, pueden ser capaces de cometabolizar los EOC vía la enzima AMO, mientras que los microorganismos heterótrofos son también capaces de degradar una gran variedad de EOC a través de sus diversas monooxigenasas y/o dioxigenasas. Además, se ha encontrado que puede haber cooperación entre las bacterias amonio oxidantes y heterótrofas e incrementar la degradación de los EOC (Khunjar et al., 2011; Tran et al., 2013).

El empleo de bacterias nitrificantes sin embargo no asegura la mineralización del compuesto que se pretenda eliminar, así por ejemplo puede conseguirse una transformación parcial del compuesto pero sin llevarlo hasta $\mathrm{CO}_{2}$. Además, el compuesto orgánico y/o sus intermediarios pueden inhibir algún paso del proceso de nitrificación o producir daño celular (Campos et al., 2001; Khunjar et al., 2011; Martínez-Hernández et al., 2011). 
2.- Antecedentes

En la literatura, la información sobre la biodegradación de antibióticos por consorcios nitrificantes es todavía escasa, así como sobre el efecto de estos fármacos en el proceso de nitrificación. Gomez et al. (1996) evaluaron por separado y a distintas concentraciones el efecto de cinco antibióticos sobre la nitrificación: ampicilina (0 a $250 \mathrm{mg} / \mathrm{L}$ ) y benzilpenicilina ( 0 a $250 \mathrm{mg} / \mathrm{L}$ ) que son $\beta$-lactámicos inhibidores de la formación de la pared celular, oxitetraciclina ( 0 a $250 \mathrm{mg} / \mathrm{L}$ ) y cloranfenicol (0 a $50 \mathrm{mg} / \mathrm{L})$, los cuales son inhibidores de la síntesis de proteínas, y novobiocina ( 0 a $150 \mathrm{mg} / \mathrm{L}$ ), un inhibidor de la síntesis de ADN. Se empleó como fuente de inóculo para los ensayos en lote, un lodo nitrificante estabilizado bajo condiciones litoautotróficas en un reactor aireado continuo. El porcentaje de eliminación de $\mathrm{NH}_{4}{ }^{+}$dentro del reactor continuo fue de $95 \%$ con una velocidad volumétrica de entrada de amonio de $151.50 \mathrm{mg} \mathrm{N}-\mathrm{NH}_{4}{ }^{+} / \mathrm{L} \cdot \mathrm{d}$. La tasa de nitrificación fue de $2.91{\mathrm{~g} \mathrm{~N}-\mathrm{NO}_{3}}^{-} / \mathrm{g} \mathrm{N}_{\text {-biomasa }} \cdot \mathrm{d}$ y no se observó nitrito bajo las condiciones de operación. Los ensayos en lote se llevaron a cabo en matraces de $250 \mathrm{~mL}$, mantenidos en agitación $\left(190 \mathrm{rpm}, 26^{\circ} \mathrm{C}, \mathrm{pH}=7.7\right)$, en ausencia de luz y aireación continúa durante 80 h. Los autores utilizaron las siguientes variables de respuesta para evaluar la nitrificación en lote en presencia de los diferentes antibióticos: la tasa específica máxima de crecimiento ( $\mu$, $1 / \mathrm{h})$ y la tasa volumétrica de nitrificación $(\mathrm{Q}, \mathrm{g} / \mathrm{L} \cdot \mathrm{h})$ determinada después del fin de la fase lag como $\mathrm{Q}=\Delta \mathrm{NO}_{3}{ }^{-} / \mathrm{t}$, donde $\Delta \mathrm{NO}_{3}{ }^{-}$es el incremento de la concentración de nitrato $(\mathrm{g} / \mathrm{L})$ en el tiempo transcurrido (t). Para cada antibiótico, no se observó diferencia al comparar el perfil de crecimiento microbiano y producción de nitrato entre el ensayo control sin antibiótico y los ensayos con diferentes concentraciones iniciales de antibiótico. Tampoco se observaron diferencias en los perfiles cinéticos entre los distintos antibióticos. Se reportaron valores promedio para todos los antibióticos evaluados e incluyendo los controles de: $\mu=8.28 \times 10^{-3} \pm 8.4 \times 10^{-5} 1 / \mathrm{h}$ y Q $=2.74 \times 10^{-3} \pm 2.8 \times 10^{-4} \mathrm{~g} / \mathrm{L} \cdot \mathrm{h}$. Para la ampicilina, los valores fueron: $\mu=8.30 \times 10^{-3} \pm 7.5 \times 10^{-5} 1 / \mathrm{h}$ y $\mathrm{Q}=2.93 \times 10^{-3} \pm 1.0 \times 10^{-}$ ${ }^{4} \mathrm{~g} / \mathrm{L} \cdot \mathrm{h}$. Se concluyó que no se produjo un efecto significativo sobre las tasas del proceso de nitrificación y que posiblemente esto se debió a que el flóculo constituye una barrera 
selectiva y protectora, y de esta forma el lodo nitrificante no sea sensible a los antibióticos estudiados.

Si bien Gómez y colaboradores evaluaron el efecto de la ampicilina y otros antibióticos sobre el proceso nitrificante a través de variables de respuesta como: tasa específica de crecimiento celular y velocidad volumétrica de formación de nitrato, no presentaron información detallada del proceso respiratorio nitrificante en lote a través de variables como las velocidades específicas de consumo de amonio así como de formación de nitrito y nitrato para cada concentración de antibiótico. En ningún caso, se presentaron rendimientos y eficiencias. No hubo tampoco evaluación de la capacidad del lodo para biotransformar los diferentes antibióticos bajo las condiciones nitrificantes.

Li y Zhang (2010) estudiaron la eliminación por lodos activados de la ampicilina y otros 10 antibióticos presentes comúnmente en aguas de desecho de Hong Kong (China). Se efectuaron dos series de experimentos en lote con licor mezclado fresco de los tanques de aireación de dos plantas de tratamiento locales, una que trataba aguas de desecho salinas y otra que trataba aguas de desecho dulces. Los experimentos en lote se realizaron en recipientes de vidrio de $2 \mathrm{~L}$ con $1 \mathrm{~L}$ de licor mezclado mantenidos a $22 \pm 1^{\circ} \mathrm{C}$ y una agitación de $150 \mathrm{rpm}$ por $48 \mathrm{~h}$. Se realizaron diferentes tratamientos a fin de diferenciar las vías de eliminación de estos antibióticos por biodegradación, adsorción, volatilización o hidrólisis. La concentración inicial de antibiótico en los reactores en lote fue de $100 \mu \mathrm{g} / \mathrm{L}$. De acuerdo a los autores, los resultados sugirieron que ninguno de los antibióticos tuvo efecto sobre la actividad biológica. En ensayos control, se comprobó que todos los antibióticos fueron estables, sin que ocurriera hidrólisis durante el periodo de prueba. Además, de acuerdo a los resultados, así como a las características de los compuestos (constantes de la ley de Henry muy bajas: $4.97 \times 10^{-31}$ a $1.58 \times 10^{-10} \mathrm{~atm} \cdot \mathrm{m}^{3} / \mathrm{mol}$, peso molecular alto: >200 y presencia de grupos polares), la volatilización se consideró despreciable. Los autores mencionaron que la principal ruta de eliminación de la ampicilina fue la adsorción en el lodo activado. En los primeros 15 minutos, se adsorbió cerca de $56.8 \%$ de la ampicilina en aguas de drenaje dulces y $38.7 \%$ en aguas de drenaje salinas, alcanzándose el equilibrio a las $10 \mathrm{~h}$ en ambos sistemas. Si bien en este trabajo se distinguen las vías de eliminación de la ampicilina, se usó un lodo activado sin actividad nitrificante especificada, por lo que el proceso nitrificante no se evaluó. 
Labinghisa y Rollon (2014), empleando un lodo activado procedente de un sistema de tratamiento de aguas de desecho de un centro comercial, estudiaron la eliminación de ampicilina en un reactor aerobio de membrana (MBR). Se utilizaron membranas de diferentes materiales y se determinó el mecanismo de eliminación por el lodo adherido sobre éstas. Parte del lodo fue sometido a un proceso de aclimatación de 1 mes para promover su actividad nitrificante alimentándolo con medio nitrificante (reactor B). Una vez que se consiguió la nitrificación con un consumo de $\mathrm{N}_{-} \mathrm{NH}_{4}{ }^{+}$y una producción de $\mathrm{N}$ $\mathrm{NO}_{3}{ }^{-}$estables, se añadió ampicilina tanto al reactor $\mathrm{B}$ con actividad nitrificante como al reactor A sin actividad nitrificante (1 a $100 \mu \mathrm{g} / \mathrm{L})$. La ampicilina se monitoreó cada 3-4 días. Las autoras mencionan que la eliminación de ampicilina se llevó a cabo con ambos lodos sin embargo, el promedio de eliminación con el lodo sin actividad nitrificante fue de $78.13 \%$ mientras que fue de $87.60 \%$ para el lodo con actividad nitrificante. Las membranas hidrofóbicas presentaron las mayores capacidades de eliminación (polietersulfona: 47\% y difluoruropolivilideno: 54\%) y la membrana hidrofílica de nylon presentó la menor capacidad de eliminación (32\%). Se reportó que en el reactor de membrana, la ampicilina se retiró a través de la biodegradación, filtración por membrana y/o adsorción al lodo depositado en ella, siendo estos dos últimos los mecanismos más importantes. En este trabajo, no se dan detalles de la actividad nitrificante del inóculo inicial, así como tampoco se evaluó el proceso de nitrificación en cada uno de los sistemas con los diferentes lodos. Además, no se cuantificó la parte de ampicilina eliminada por biodegradación, adsorción al lodo o eliminación por factores abióticos. De acuerdo a estos antecedentes, queda claro que es necesario un mayor estudio para entender mejor cual podría ser el papel de los lodos nitrificantes en la eliminación por biodegradación de la ampicilina de aguas residuales, así como cuál sería el efecto de este antibiótico sobre el proceso de nitrificación en el tratamiento de aguas.

\section{3.- Justificación}

Entre los llamados contaminantes emergentes, los antibióticos son importantes debido a que se presentan aún en efluentes de plantas de tratamiento, contribuyendo a la contaminación de los cuerpos receptores de agua y a la resistencia bacteriana por antibióticos. El 
antibiótico ampicilina es uno de los $\beta$-lactámicos más ampliamente usados. Algunos efluentes (urbanos e industriales) se caracterizan por tener amonio y antibióticos como contaminantes. La contaminación del agua por nitrógeno se da principalmente por la presencia de amonio en aguas residuales, es importante contar entonces con tratamientos que puedan eliminar nitrógeno amoniacal como lo es el acoplamiento de los procesos biológicos de nitrificación y desnitrificación. Estos procesos acoplados permiten la oxidación de amonio a nitrógeno molecular. Se ha reportado que los consorcios nitrificantes pueden ser capaces de oxidar simultáneamente amonio y compuestos orgánicos, incluyendo compuestos orgánicos emergentes de difícil biodegradación. La información sobre el papel de los lodos nitrificantes en la eliminación de antibióticos es aún escasa, por lo que se requieren más estudios a fin de aumentar el conocimiento sobre el comportamiento de los lodos nitrificantes en presencia de antibióticos así como sobre el efecto de éstos sobre el proceso de nitrificación en el tratamiento de aguas. En el caso de la ampicilina, los estudios en este tema son escasos y los existentes generalmente no mencionan variables de respuesta como velocidades, eficiencias de consumo y rendimientos tanto de la nitrificación como de la biotransformación del antibiótico. Estas variables de respuesta pueden ayudar a entender el comportamiento fisiológico de consorcios nitrificantes en presencia de ampicilina.

\section{4.- Hipótesis}

Un consorcio bacteriano con actividad nitrificante estable será capaz de biotransformar el antibiótico ampicilina.

\section{5.- Objetivo general}

Evaluar la capacidad de un cultivo nitrificante en la biotransformación de amonio y ampicilina en cultivos en lote. 


\subsection{Objetivos particulares}

1) Estudiar el efecto de la ampicilina sobre el metabolismo de un consorcio nitrificante.

2) Evaluar la capacidad de un cultivo nitrificante en la oxidación de amonio y ampicilina.

3) Evaluar la contribución de los procesos de biotransformación y biosorción en la eliminación de ampicilina. por el lodo nitrificante.

6.- Materiales y Métodos

\subsection{Reactor nitrificante en continuo}

Se empleó un reactor nitrificante en continuo de tanque agitado como fuente de inóculo para los cultivos en lote con un volumen nominal de 10 L y volumen de operación de 6 L, con agitación de $300 \mathrm{rpm}$, flujo de aire de $224 \pm 0.04 \mathrm{~mL} / \mathrm{min}$ y un tiempo de residencia hidráulico de $2.24 \pm 0.02$ d (Fig. 5). La alimentación del reactor se realizó con dos medios de cultivo como fuentes de nitrógeno y carbono, suministrados por separado a través de bombas peristálticas (Master Flex, ColeParmer), controladas por un temporizador. Los componentes de los medios de cultivo se muestran en la Tabla 1. La relación $\mathrm{C} / \mathrm{N}$ fue de 3.12 con una velocidad de carga de $162.21 \pm 5.1 \mathrm{mg} \mathrm{N}-\mathrm{NH}_{4}{ }^{+} / \mathrm{L} \cdot \mathrm{d}$ y para el C-NaHCO${ }_{3}$ de $511.30 \pm 27 \mathrm{mg} \mathrm{C} / \mathrm{L}^{\bullet} \mathrm{d}$. El valor promedio de $\mathrm{pH}$ en el cultivo dentro del reactor fue de 7.85 \pm 0.5 . La concentración promedio en biomasa microbiana fue de $537.70 \pm 38.4 \mathrm{mg}$ proteína/L. 


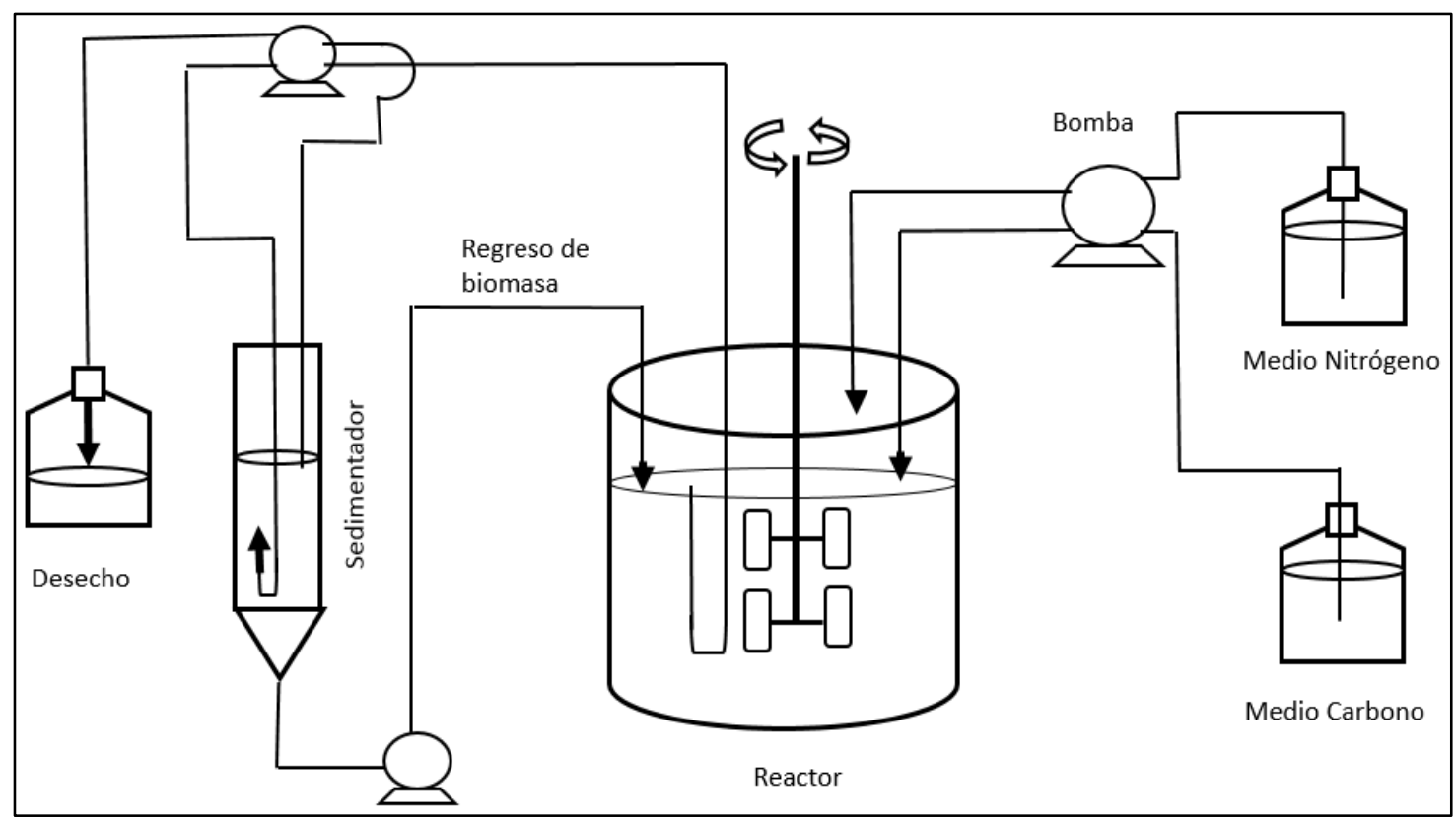

Figura 5. Esquema del reactor nitrificante en continuo.

Tabla 1. Composición del medio de cultivo para el reactor nitrificante en continuo.

\begin{tabular}{llll}
\hline $\begin{array}{l}\text { Fuente de nitrógeno } \\
\text { Sales }\end{array}$ & $\begin{array}{l}\text { Concentración } \\
(\mathrm{g} / \mathrm{L})\end{array}$ & $\begin{array}{l}\text { Fuente de carbono } \\
\text { Sales }\end{array}$ & $\begin{array}{l}\text { Concentración } \\
(\mathrm{g} / \mathrm{L})\end{array}$ \\
\hline$\left(\mathrm{NH}_{4}\right)_{2} \mathrm{SO}_{4}$ & 1.73 & $\mathrm{NaHCO}_{3}$ & 16.00 \\
\hline $\mathrm{NH}_{4} \mathrm{Cl}$ & 1.39 & $\mathrm{CaCl}_{2}$ & 0.05 \\
\hline $\mathrm{KH}_{2} \mathrm{PO}_{4}$ & 2.73 & & \\
\hline $\mathrm{MgSO}$ & & \\
\hline $\mathrm{NaCl}$ & 1.23 & & \\
\hline
\end{tabular}

El efluente del reactor se bombea a un sedimentador $(8 \mathrm{~cm}$ de diámetro por $92 \mathrm{~cm} \mathrm{de}$ largo), con la finalidad de concentrar en su parte inferior la biomasa sedimentada y regresarla al tanque agitado. El efluente clarificado se retira de la parte superior del sedimentador. Con el fin de evaluar el desempeño de este reactor nitrificante, se cuantificó el amonio, nitrito y nitrato en el efluente así como la proteína microbiana dentro del tanque 
agitado. El lodo proveniente del reactor se lavó con solución salina $(0.9 \%$ p/v de $\mathrm{NaCl})$ para retirar el medio así como partículas finas, antes de usarlo como inóculo en los ensayos en lote (Silva Luna, 2011).

\subsection{Cultivos nitrificantes en lote y ensayos abióticos}

Los ensayos en lote se realizaron en botellas serológicas de $160 \mathrm{~mL}$ con un volumen de trabajo de $100 \mathrm{~mL}$. El medio de cultivo se presenta en la Tabla 2. La concentración inicial de amonio que se usó fue de $103.07 \pm 0.5 \mathrm{mg}$ de $\mathrm{N}_{-} \mathrm{NH}_{4}{ }^{+} / \mathrm{L}$ con una relación $\mathrm{C} / \mathrm{N}$ de 2.42 y una concentración en biomasa por botella de $320.00 \pm 8 \mathrm{mg}$ de proteína bacteriana/L. A cada botella, se le adicionó $0.25 \mathrm{~mL}$ de una solución al $5 \%$ (p/v) de $\mathrm{FeSO}_{4} \cdot 7 \mathrm{H}_{2} \mathrm{O}$ (Meiklejohn, 1953). Cabe mencionar que los valores de $\mathrm{pH}$ para todos los ensayos fueron de $8.4 \pm 0.1$ y $5.8 \pm 0.3$ para el tiempo cero y a las $24 \mathrm{~h}$ de cultivo, respectivamente. Una vez preparado el medio, se adicionó la ampicilina a concentraciones iniciales de 10, 25 y 50 $\mathrm{mg} / \mathrm{L}$ en los ensayos con ampicilina.

Tabla 2. Composición del medio de cultivo para los cultivos nitrificantes en lote.

\begin{tabular}{llll}
\hline $\begin{array}{l}\text { Fuente de nitrógeno } \\
\text { Sales }\end{array}$ & $\begin{array}{l}\text { Concentración } \\
(\mathrm{g} / \mathrm{L})\end{array}$ & $\begin{array}{l}\text { Fuente de carbono } \\
\text { Sales }\end{array}$ & $\begin{array}{l}\text { Concentración } \\
(\mathrm{g} / \mathrm{L})\end{array}$ \\
\hline$\left(\mathrm{NH}_{4}\right)_{2} \mathrm{SO}_{4}$ & 0.19 & $\mathrm{NaHCO}_{3}$ & 1.75 \\
\hline $\mathrm{NH}_{4} \mathrm{Cl}$ & 0.24 & $\mathrm{CaCl}_{2}$ & 0.01 \\
\hline $\mathrm{KH}_{2} \mathrm{PO}_{4}$ & 0.28 & & \\
\hline $\mathrm{MgSO}$ & & & \\
\hline $\mathrm{NaCl}$ & 0.20 & & \\
\hline
\end{tabular}

En cada botella serológica, se añadió primero el lodo nitrificante y en seguida el medio conteniendo la ampicilina, después se burbujeó en el líquido oxígeno puro (99.6\%) por 3 min. La botella se selló con tapón de hule y en el espacio de cabeza se inyectó oxígeno puro por dos minutos, para finalmente cubrir con parafilm el tapón de hule y borde de la boca de la botella antes de colocar un anillo de aluminio. La concentración inicial en oxígeno disuelto fue de $6.4 \pm 0.2 \mathrm{mg} / \mathrm{L}$. Las botellas se llevaron a una incubadora a $25{ }^{\circ} \mathrm{C}$ con agitación de 300 rpm. La duración de los cultivos fue de 24 h. Cada botella se "sacrificó" a 
un tiempo determinado, el contenido se centrifugó (4000 rpm, 2 min) y el sobrenadante se filtró $(0.2 \mu \mathrm{m})$ antes de su análisis. Según el caso, se determinó la concentración de ampicilina, amonio, nitrito, nitrato, carbono orgánico total (COT), y proteína bacteriana.

Los diferentes ensayos en lote que se realizaron fueron los siguientes:

A) Ensayos abióticos (sin biomasa) con las concentraciones de ampicilina antes mencionadas a fin de determinar la eliminación abiótica de la ampicilina en el sistema experimental y bajo las condiciones experimentales utilizadas. En este tipo de ensayos, se excluye la biotransformación y adsorción por la biomasa, sólo pueden ocurrir procesos físico-químicos en la eliminación del antibiótico, tales como hidrólisis, reacción química con los componentes del medio y adsorción en la unidad experimental.

B) Ensayos de adsorción con una masa determinada de lodo nitrificante y ampicilina a concentraciones de 10, 25 y $50 \mathrm{mg} / \mathrm{L}$, en el medio nitrificante sin oxígeno para detener la actividad biológica aerobia. Con estos ensayos, se evaluó la capacidad del lodo en adsorber el antibiótico de acuerdo a la metodología propuesta por Hamon et al. (2014). Se siguió la misma metodología previamente descrita para los cultivos en lote pero en vez de inyectar oxígeno, se empleó gas nitrógeno tanto en el medio líquido como en el espacio de cabeza. En estos ensayos sin oxígeno, se excluye sólo la biotransformación aerobia, pueden estar presentes los procesos de hidrólisis, reacción química con los componentes del medio, adsorción en la unidad experimental y biosorción.

C) Cultivos nitrificantes con el antibiótico ampicilina (10, 25 y $50 \mathrm{mg} / \mathrm{L})$ y sus respectivos ensayos control sin adición de ampicilina. Con esta serie de ensayos, se evaluó el efecto de la ampicilina sobre el proceso de la nitrificación, así como la biotransformación del antibiótico para cada concentración. Están presentes todos los procesos de eliminación de ampicilina: biotransformación, biosorción y procesos físico-químicos.

La parte de eliminación debida a procesos fisicoquímicos se evaluó mediante los resultados de los ensayos A, la biosorción mediante la comparación de los resultados de los ensayos B y A y la biotransformación mediante la comparación de los resultados de los ensayos C y B. En todos los ensayos, se incluyeron duplicados. Para el ajuste de curvas, se empleó el complemento Solver (Microsoft Excel 2013). 


\subsection{Variables de respuesta}

Las variables de respuesta eficiencia y rendimiento proporcionan la información global del proceso y con ellas es posible evaluar el efecto de la ampicilina en la actividad nitrificante y su biotransformación por el lodo. Se utilizaron las siguientes ecuaciones:

Eficiencia en el consumo de un sustrato:

$$
\text { E sustrato }(\%)=\left[\frac{(C \text { sustrato inicial })-(C \text { sustrato final })}{C \text { sustrato } \text { inicial }}\right] 100
$$

Rendimiento de producto respecto al sustrato consumido:

$$
Y \text { producto }=\frac{(C \text { producto final })-(C \text { producto inicial })}{(C \text { sustrato inicial })-(C \text { sustrato final })}
$$

Se determinaron las eficiencias de consumo de amonio y ampicilina, y los rendimientos de los siguientes productos: nitrito, nitrato, y biomasa. Los rendimientos de nitrito y nitrato proporcionan información del proceso catabólico de la nitrificación (proceso respiratorio nitrificante) mientras que el rendimiento de biomasa proporciona información del proceso anabólico de la nitrificación (asimilación de nitrógeno de amonio). De esta forma, se puede evaluar el efecto de la ampicilina sobre el metabolismo del consorcio nitrificante.

Para evaluar la parte cinética del proceso nitrificante, se determinaron las velocidades específicas de consumo de amonio $\left(\mathrm{Q}_{\mathrm{NH} 4}\right)$ y producción de nitrato $\left(\mathrm{Q}_{\mathrm{NO} 3}\right)$. La $\mathrm{Q}_{\mathrm{NH} 4}$ es la variable de respuesta del proceso amonio oxidante mientras que la $\mathrm{Q}_{\mathrm{NO} 3}$ es la variable de respuesta de la nitrito oxidación. De la misma forma, se calculó la velocidad específica de consumo de la ampicilina $\left(\mathrm{Q}_{\mathrm{amp}}\right)$. Velocidad específica: $\mathrm{Q}=\mathrm{V} / \mathrm{X}$ donde $\mathrm{V}$ es la velocidad volumétrica inicial de consumo de sustrato o formación de producto y $\mathrm{X}$ la concentración celular. Para el cálculo de desviación en las velocidades, se empleó:

$$
\sigma=\sqrt{\left[\frac{\sum(y i-(m x i-b))^{2}}{n-2}\right]\left[\frac{1}{\sum(x i-\overline{\mathrm{x}})^{2}}\right]}
$$

Siendo $y i, x i$ los datos, $m$ y $b$ la pendiente y la ordenada al origen respectivamente de la recta ajustada por mínimos cuadrados al inicio de la curva utilizada para el cálculo de la velocidad volumétrica inicial. 


\subsection{Métodos analíticos}

\subsubsection{Cuantificación de amonio}

Para medir el amonio en el medio de cultivo se utilizó un potenciómetro portátil (DigiSense, Cole-Parmer) acoplado con un electrodo de ion selectivo de membrana permeable al amoniaco (pHoenix electrode Co. Mod. NH331501). El método se basa en elevar el valor de $\mathrm{pH}$ de la muestra a fin de desplazar el equilibrio del par $\mathrm{NH}_{4}{ }^{+} / \mathrm{NH}_{3}$ hacia la formación de amoniaco gaseoso. Para esto, se adicionaron $0.5 \mathrm{~mL}$ de una solución de $\mathrm{NaOH} 10 \mathrm{~N}$ a $50 \mathrm{~mL}$ de muestra y se mantuvo bajo agitación constante a temperatura ambiente. La lectura del potenciómetro se tomó después de tres minutos de haber adicionado el $\mathrm{NaOH}$. Mediante la curva de calibración (Fig. 6) fue posible calcular la concentración de amonio en la muestra a través de la ecuación: Potencial $(\mathrm{mV})=m$ logaritmo $\left(\left[\mathrm{NH}_{4}{ }^{+}\right]\right)+b$, la cual se transforma a: $\left[\mathrm{NH}_{4}{ }^{+}\right]=$antilog $(($Potencial- $b) / m)$ donde $m$ es la pendiente y $b$ la ordenada al origen de la curva de calibración.

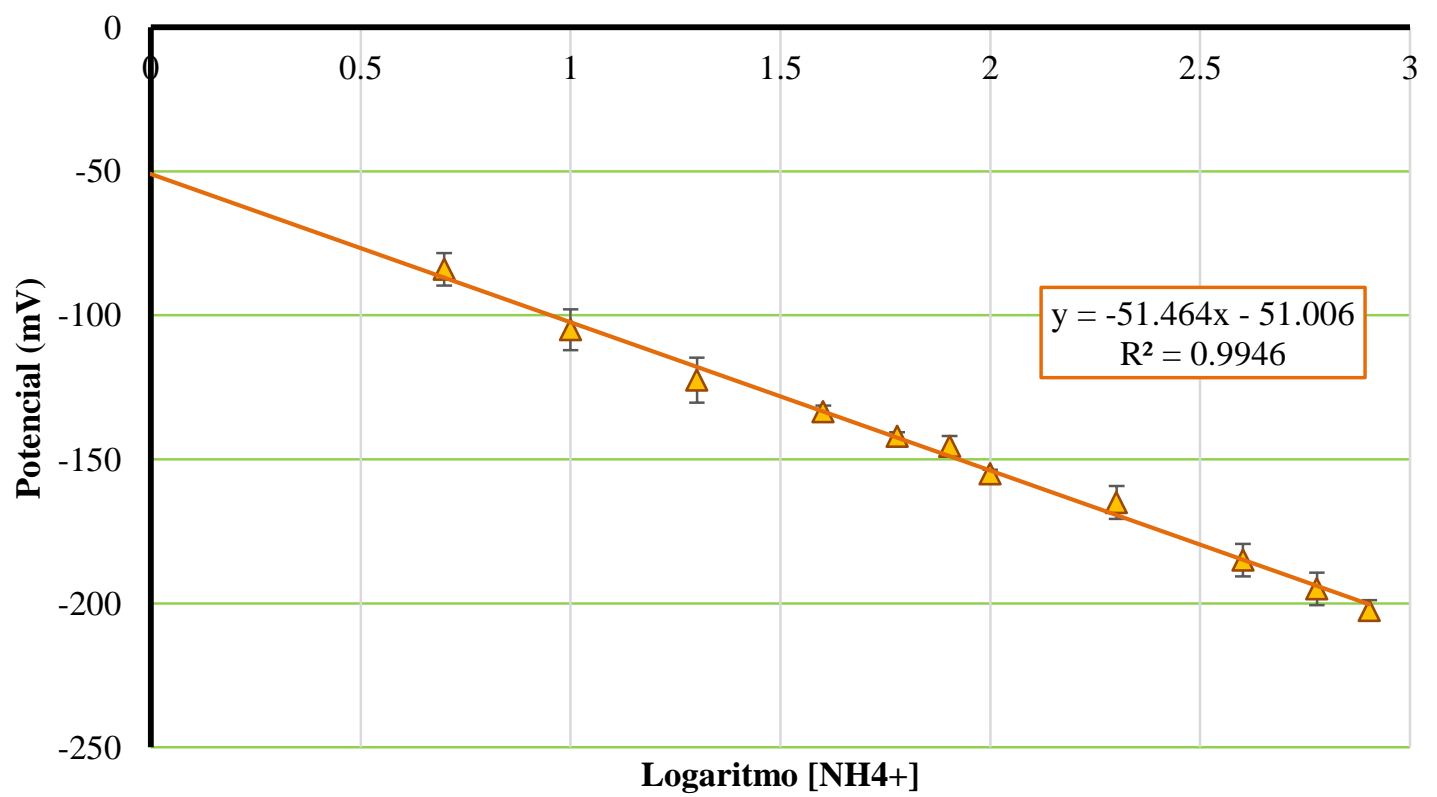

Figura 6. Curva de calibración de amonio empleando una membrana de ion selectivo de amoniaco. 


\subsubsection{Cuantificación de nitrito y nitrato}

La cuantificación de nitrito y nitrato en las muestras se efectuó por cromatografía de líquidos (HPLC) con un equipo Perkin Elmer serie 200, una columna IC-Pak anion HC (4.6 x $150 \mathrm{~mm}$ ) (Waters) y un detector UV/VIS a una longitud de onda de $214 \mathrm{~nm}$. La fase móvil fue compuesta de: $20 \mathrm{~mL}$ de $n$-butanol, $120 \mathrm{~mL}$ de acetonitrilo y $20 \mathrm{~mL}$ de una solución borato-gluconato, llevados con agua desionizada a un volumen final de $1 \mathrm{~L}$. La solución borato-gluconato fue preparada con $16 \mathrm{~g}$ de gluconato de sodio, $18 \mathrm{~g}$ de ácido bórico, $25 \mathrm{~g}$ de tetraborato decahidratado de sodio, $250 \mathrm{~mL}$ de glicerol llevados a $1 \mathrm{~L}$ con agua desionizada. El flujo fue de $2 \mathrm{~mL} / \mathrm{min}$. Las muestras fueron filtradas (membrana de nylon, $0.2 \mu \mathrm{m})$ y colocadas en viales para su análisis. En cada corrida, se analizaron soluciones estándares de concentración conocida o se realizaron curvas de calibración (Fig. 7).

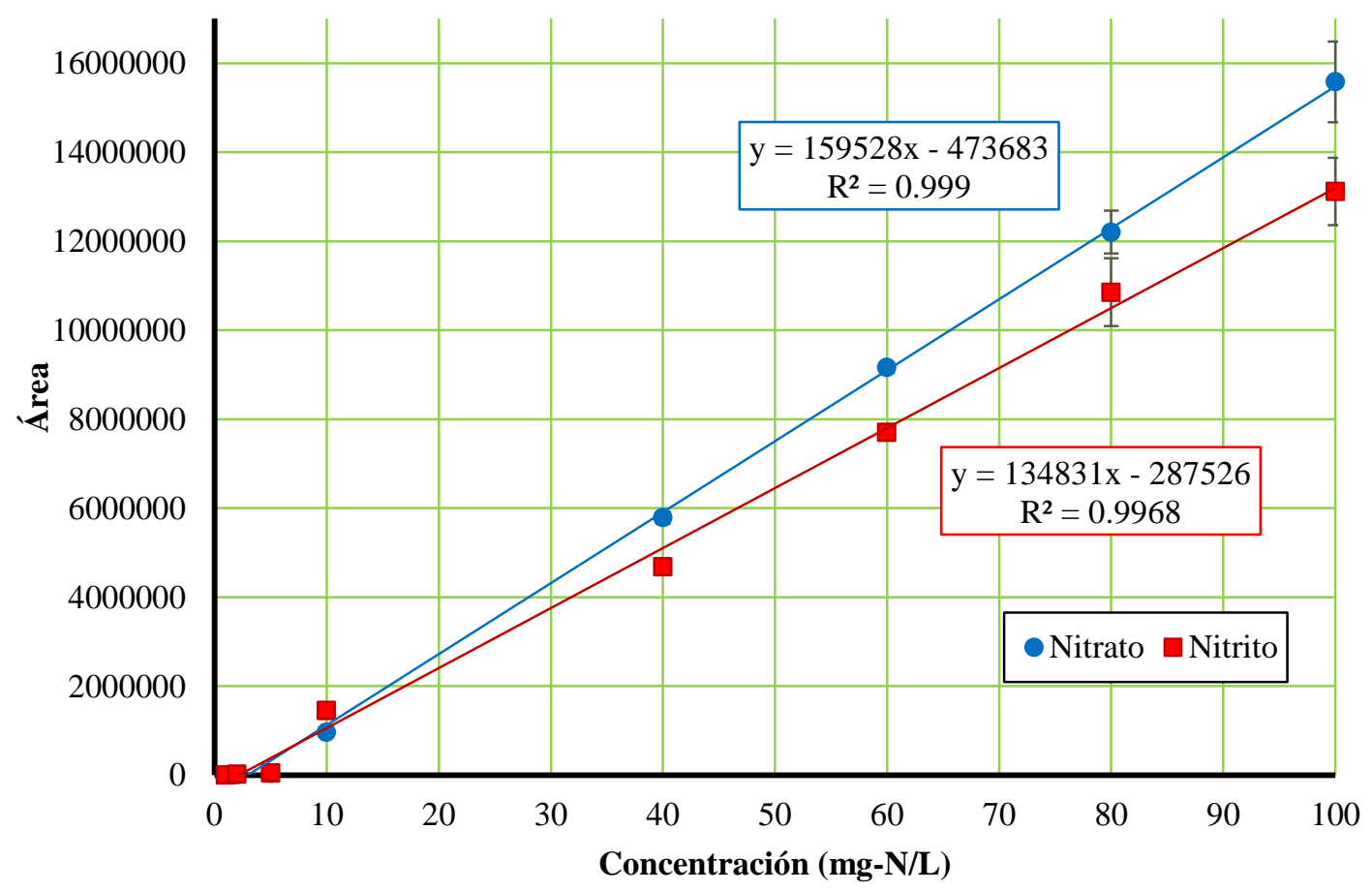

Figura 7. Curvas de calibración de nitrito y nitrato por cromatografía de líquidos (HPLC). 


\subsubsection{Cuantificación de carbono orgánico total}

El método se basa en la propiedad de absorción de radiación infrarroja que presenta el $\mathrm{CO}_{2}$. Para la cuantificación de carbono orgánico e inorgánico de las muestras, se utilizó un analizador de carbono orgánico total (COT) (Shimadzu, TOC-VCSN). El analizador determina el carbono total $(\mathrm{CT}=\mathrm{COT}+\mathrm{CI})$ y el carbono inorgánico $(\mathrm{CI})$ y por diferencia entre ellos determina la concentración de carbono orgánico total $(\mathrm{COT}=\mathrm{CT}-\mathrm{CI})$. Para determinar el carbono total, en el equipo la muestra se transporta en aire de alta pureza hasta el sitio de combustión $\left(680^{\circ} \mathrm{C}\right)$ que contiene un catalizador donde el carbono es oxidado a $\mathrm{CO}_{2}$. El gas secado y enfriado se detecta empleando un analizador infrarrojo. El área que da el analizador de datos es proporcional a la concentración de carbono total presente en la muestra. Para cuantificar el carbono inorgánico, la muestra es acidificada en el equipo (ácido fosfórico al 25\% v/v) y con burbujeo del gas acarreador, el carbono inorgánico disuelto (bicarbonato y carbonato) se lleva a $\mathrm{CO}_{2}$, siendo el análisis como el del carbono total. El tratamiento previo al análisis de las muestras fue una centrifugación por 10 min a $4000 \mathrm{rpm}$ seguida de una filtración (membrana de nylon, $0.2 \mu \mathrm{m}$ ). Se presentan las curvas de calibración obtenidas para el carbono total e inorgánico en la Fig. 8.

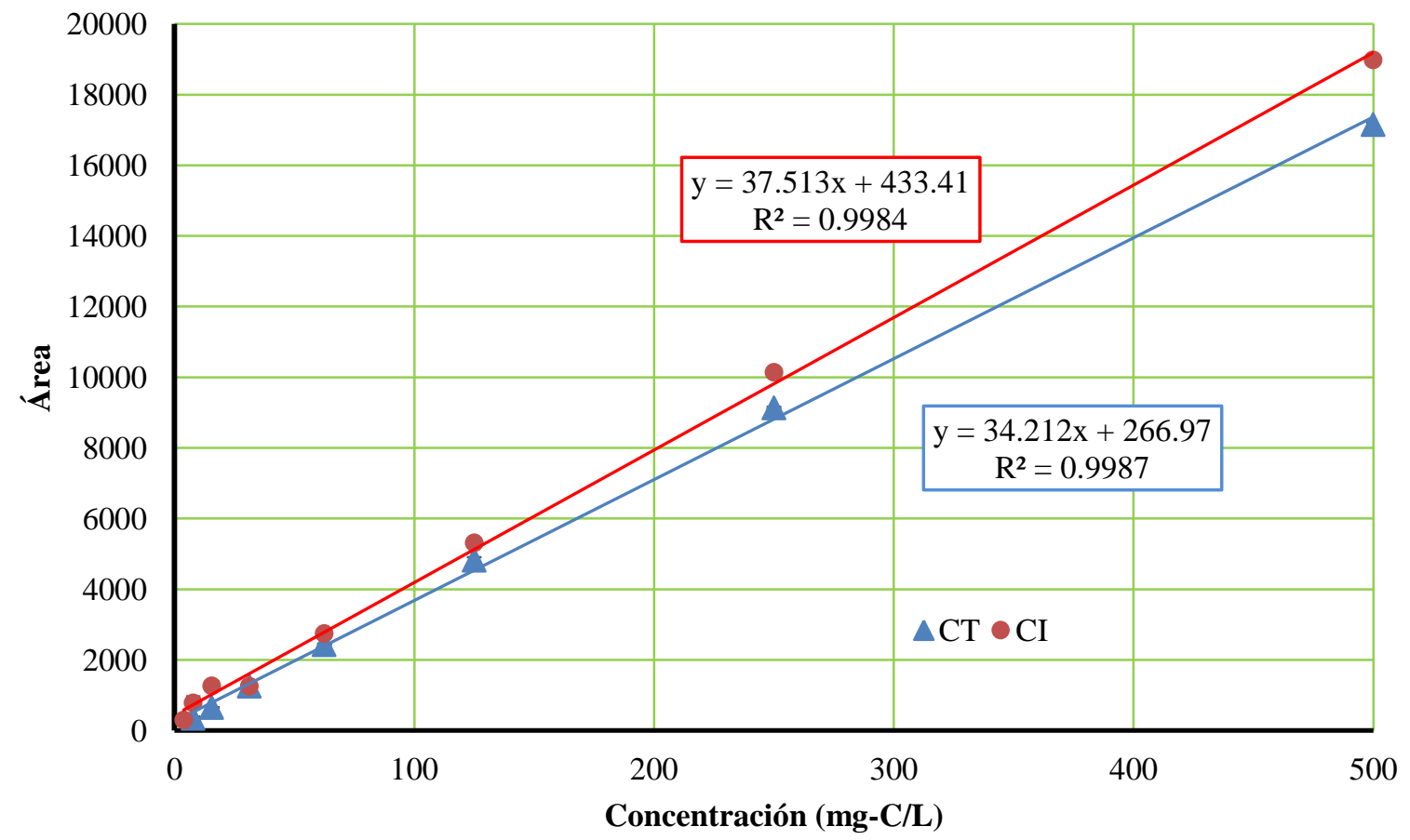

Figura 8. Curvas de calibración de carbono total (CT) y carbono inorgánico (CI). 


\subsubsection{Cuantificación de proteína bacteriana}

Se empleó el método colorimétrico de Lowry (Lowry et al., 1951) modificado de acuerdo a la metodología propuesta por Martínez et al. (2000). El método se basa en la formación del complejo Cu-proteína y la posterior reducción de éste por el reactivo de Folin-Ciocalteau. El reactivo de Folin-Ciocalteau (Hycel) formado por molibdato, fosfato y tungstato de sodio tiene un máximo de absorción a $750 \mathrm{~nm}$. Se requiere que las proteínas presenten aminoácidos con grupos fenólicos que puedan enlazarse con el $\mathrm{Cu}^{2+}$. Se prepararon tres soluciones: $a$ ).- $\mathrm{Na}_{2} \mathrm{CO}_{3} 0.19 \mathrm{M}$ en $\mathrm{NaOH} 0.1 \mathrm{~N}, b$ ).- $\mathrm{CuSO}_{4}$ al $1 \% \mathrm{p} / \mathrm{v}, \mathrm{y} c$ ).- Tartrato de sodio y potasio al $2 \%$. Con estas soluciones, se hizo una solución de trabajo $a b c$ formada por: $1 \mathrm{~mL}$ de solución $b+1 \mathrm{~mL}$ de solución $c+48 \mathrm{~mL}$ de solución $a$. En tubos de ensaye de $10 \mathrm{~mL}$ con tapa de rosca, se colocaron $1 \mathrm{~mL}$ de muestra y $0.1 \mathrm{~mL}$ de $\mathrm{NaOH} 10 \mathrm{~N}$. La mezcla se llevó a agitación en vortex y se mantuvo en baño seco (digestión alcalina) por 20 min a $90^{\circ} \mathrm{C}$. Posteriormente, se adicionó a cada tubo $5 \mathrm{~mL}$ de la solución de trabajo abc. Los tubos se llevaron a reposo por 30 min en la oscuridad. Luego, se agregó $1 \mathrm{~mL}$ de reactivo de Folin-Ciocalteau a cada uno de ellos, dejando reposar nuevamente en la oscuridad por $1 \mathrm{~h}$, finalmente se midió la absorbancia a $750 \mathrm{~nm}$ en un espectrofotómetro UV/VIS (Shimadzu, mod. UV-1601). De acuerdo a la misma metodología, se prepararon soluciones estándares (0 - 500 mg/L) empleando albúmina bovina (Sigma, 96-99\%) y se realizó una curva decalibración (Fig. 9).

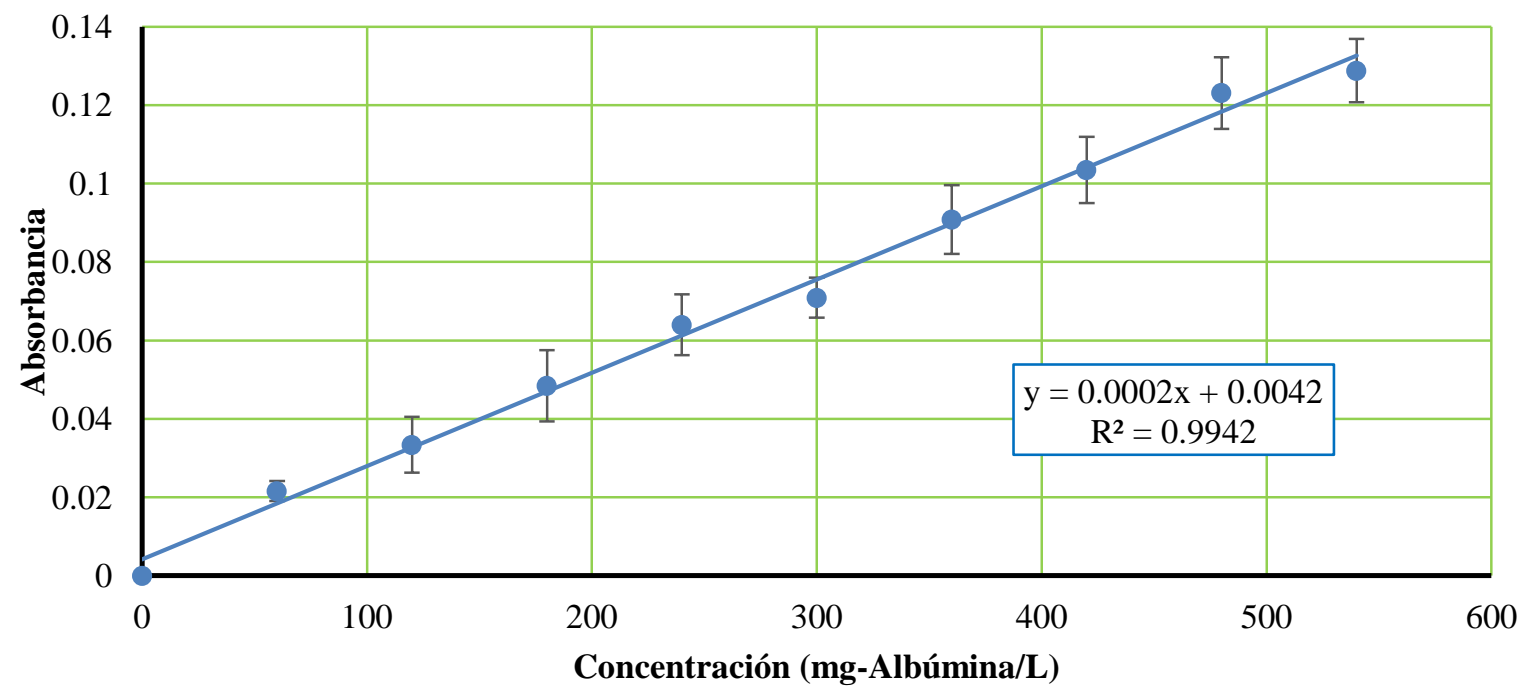

Figura 9. Curva de calibración de albúmina por espectrofotometría. 


\subsubsection{Cuantificación de ampicilina}

La cuantificación de ampicilina se realizó por cromatografía de líquidos (HPLC, Perkin Elmer serie 200) con una columna Varian $(150 \mathrm{x} 4.6 \mathrm{~mm})$ con fase estacionaria Microsorb $100 \mathrm{C} 18$ y un detector UV/VIS a una longitud de onda de $230 \mathrm{~nm}$. La fase móvil estuvo compuesta de: $100 \mathrm{~mL}$ de acetonitrilo, $80 \mathrm{~mL}$ de metanol, $10 \mathrm{~mL}$ de fosfato de potasio (1 M) y $1 \mathrm{~mL}$ de ácido acético $(1 \mathrm{~N})$ llevados a un volumen final de $1 \mathrm{~L}$ con agua desionizada. El flujo fue de $1 \mathrm{~mL} / \mathrm{min}$. Previo a su análisis, las muestras se filtraron en membrana de nylon $(0.2 \mu \mathrm{m})$. En ensayos y como estándar, se utilizó ampicilina de Sigma Aldrich (producto No. A6140). En cada corrida, se analizaron soluciones estándares de concentración conocida o se realizaron curvas de calibración (Fig. 10).

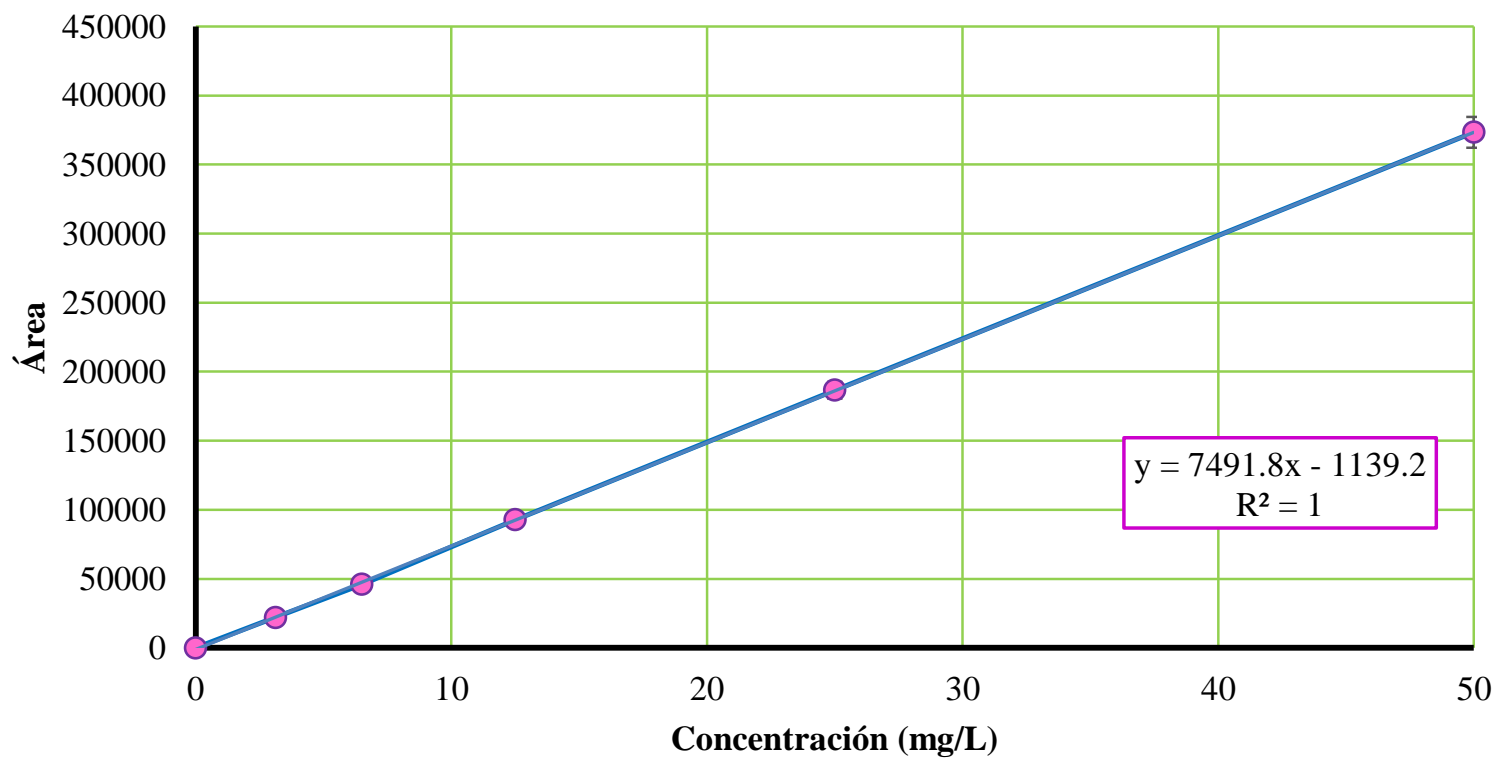

Figura 10. Curva de calibración de ampicilina por cromatografía de líquidos (HPLC).

\subsubsection{Medición de pH y oxígeno disuelto}

El pH fue medido mediante un medidor portátil (Digi-Sense, Cole Palmer) acoplado a un electrodo combinado de calomel y vidrio. El medidor de $\mathrm{pH}$ se calibró antes de realizar las mediciones experimentales de acuerdo con las instrucciones del fabricante. El oxígeno 
disuelto (OD) fue medido a través de un medidor portátil de oxígeno disuelto (Hanna instruments, modelo HI 8043). En base a las tablas del manual del equipo, se usaron los factores de corrección correspondientes para salinidad (3.5 $\mathrm{mg} / \mathrm{L}$ de sales), temperatura $\left(25^{\circ} \mathrm{C}\right)$ y presión $(0.763 \mathrm{~atm})$.

6.4.7 Reproducibilidad y linealidad de métodos

Para verificar la reproducibilidad y linealidad de los métodos analíticos empleados, se realizaron al menos tres curvas de calibración para cada técnica analítica (Tabla 3).

Tabla 3. Coeficientes de variación de las pendientes y de determinación correspondientes a las curvas de calibración realizadas con los diferentes métodos analíticos.

\begin{tabular}{lcc}
\hline Análisis & $\begin{array}{c}\text { Coeficiente } \\
\text { de variación de la } \\
\text { pendiente }(\%)\end{array}$ & $\begin{array}{c}\text { Coeficiente } \\
\text { de determinación }\left(\mathrm{R}^{2}\right)\end{array}$ \\
\hline Amonio (electrodo selectivo) & 0.2 & $0.994 \pm 0.002$ \\
\hline Nitrito (HPLC) & 0.1 & $0.993 \pm 0.006$ \\
\hline Nitrato (HPLC) & 0.1 & $0.999 \pm 0.001$ \\
\hline Carbono total (TC) & 4.0 & $0.998 \pm 0.001$ \\
\hline Carbono inorgánico (IC) & 5.3 & $0.998 \pm 0.001$ \\
\hline Proteína microbiana (Lowry) & 1.6 & $0.994 \pm 0.002$ \\
\hline Ampicilina (HPLC) & 0.1 & $0.999 \pm 0.001$ \\
\hline
\end{tabular}

Se observa que en todos los casos, el coeficiente de variación de la pendiente presentó valores menores que $5.3 \%$ y el coeficiente de determinación cercano a 1, mostrando tanto reproducibilidad como linealidad de los métodos analíticos.

7.- Resultados y discusión

\subsection{Reactor nitrificante en continuo}

El lodo empleado como inóculo en los cultivos en lote presentó una actividad nitrificante dentro del reactor en continuo (Fig. 11, Tabla 4), presentando una alta eficiencia $\left(\mathrm{E}_{\mathrm{NH} 4+}=\right.$ $99.9 \pm 0.1 \%$ ) respecto al consumo de amonio, un rendimiento en nitrato ( $\mathrm{Y}_{\mathrm{NO}}-$ ) de $0.77 \pm$ 
$0.06 \mathrm{mg} \mathrm{N}-\mathrm{NO}_{3}{ }^{-} / \mathrm{mg} \mathrm{N}^{-\mathrm{NH}_{4}}{ }^{+}$consumido y un rendimiento en biomasa microbiana ( $\mathrm{Y}_{\text {biomasa }}$ ) de $0.04 \pm 0.01 \mathrm{mg} \mathrm{N}$-Biomasa/mg $\mathrm{N}^{-\mathrm{NH}_{4}}{ }^{+}$consumido. La acumulación de nitrito fue

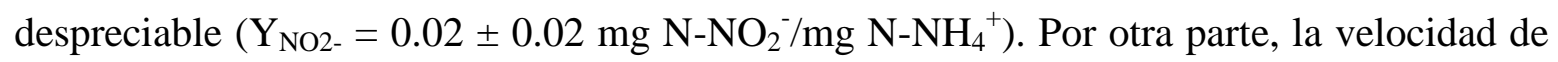
producción de nitrato fue constante a lo largo de los días $\left(123.9 \pm 9.3 \mathrm{mg} \mathrm{N}-\mathrm{NO}_{3}{ }^{-} / \mathrm{L} \bullet \mathrm{d}\right)$. Estos resultados indican que la capacidad del lodo para transformar el amonio a nitrato se llevó a cabo a través de una respiración nitrificante en estado estacionario y un proceso principalmente desasimilativo.

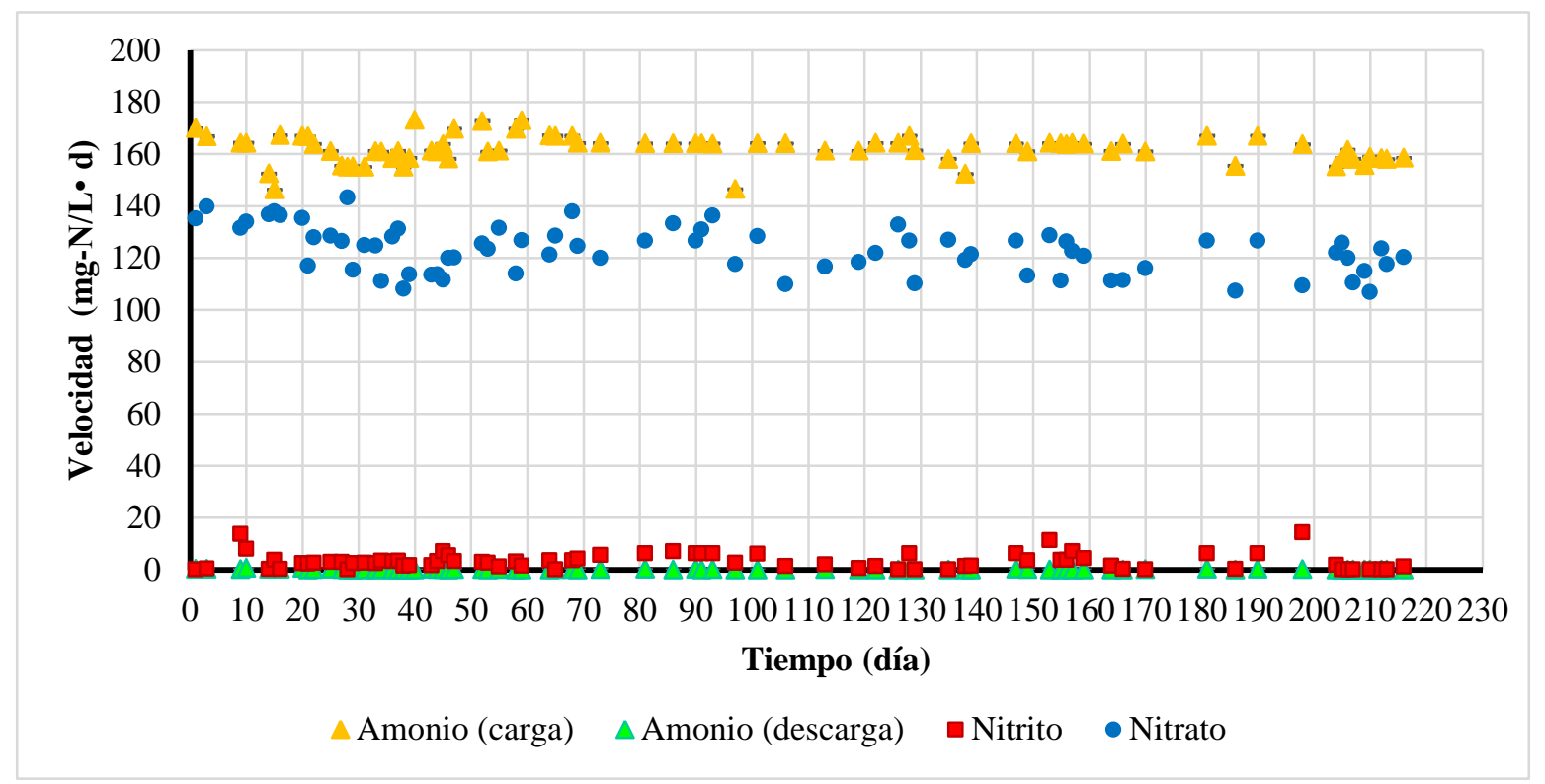

Figura 11. Perfil del reactor nitrificante en continuo.

Tabla 4. Velocidades de carga y descarga en nitrógeno, eficiencia y rendimientos ${ }^{*}(\mathrm{Y})$ del proceso nitrificante en el reactor en continuo.

\begin{tabular}{llllc}
\hline Entrada $(\mathrm{mg} \mathrm{N} / \mathrm{L} \bullet \mathrm{d})$ & \multicolumn{4}{l}{ Salida $(\mathrm{mg} \mathrm{N} / \mathrm{L} \bullet \mathrm{d})$} \\
\hline${\mathrm{N}-\mathrm{NH}_{4}{ }^{+}}$ & ${\mathrm{N}-\mathrm{NH}_{4}{ }^{+}}$ & $\mathrm{N}-\mathrm{NO}_{2}{ }^{-}$ & $\mathrm{N}^{-} \mathrm{NO}_{3}{ }^{-}$ & $\mathrm{N}-$ Biomasa \\
\hline $162.2 \pm 5.1$ & $0.15 \pm 0.1$ & $2.9 \pm 3.0$ & $123.90 \pm 9.3$ & $6.87 \pm 0.1$ \\
\hline $\mathrm{E}_{\mathrm{NH} 4+}(\%)$ & & $\mathrm{Y}_{\mathrm{NO}^{-}}$ & $\mathrm{Y}_{\mathrm{NO}^{-}}$ & $\mathrm{Y}_{\text {biomasa }}$ \\
\hline $99.9 \pm 0.1$ & & $0.02 \pm 0.02$ & $0.77 \pm 0.06$ & $0.04 \pm 0.01$ \\
\hline
\end{tabular}

${ }^{*} \mathrm{Y}_{\mathrm{NO}_{2}}^{-}, \mathrm{Y}_{\mathrm{NO}_{3}}^{-}, \mathrm{Y}_{\text {biomasa }}: \mathrm{mg} \mathrm{N} / \mathrm{mg} \mathrm{N}-\mathrm{NH}_{4}^{+}$consumido 


\subsection{Cultivos nitrificantes en lote con ampicilina}

Para cada concentración inicial de ampicilina ensayada (10, 25 y $50 \mathrm{mg} / \mathrm{L})$, se realizaron cultivos nitrificantes control en ausencia de ampicilina al mismo tiempo que los ensayos en presencia del antibiótico. Los perfiles cinéticos del proceso de nitrificación se presentan en las Fig. 12 a 14 a las diferentes concentraciones m encionad as con sus respectivos ensayos control.
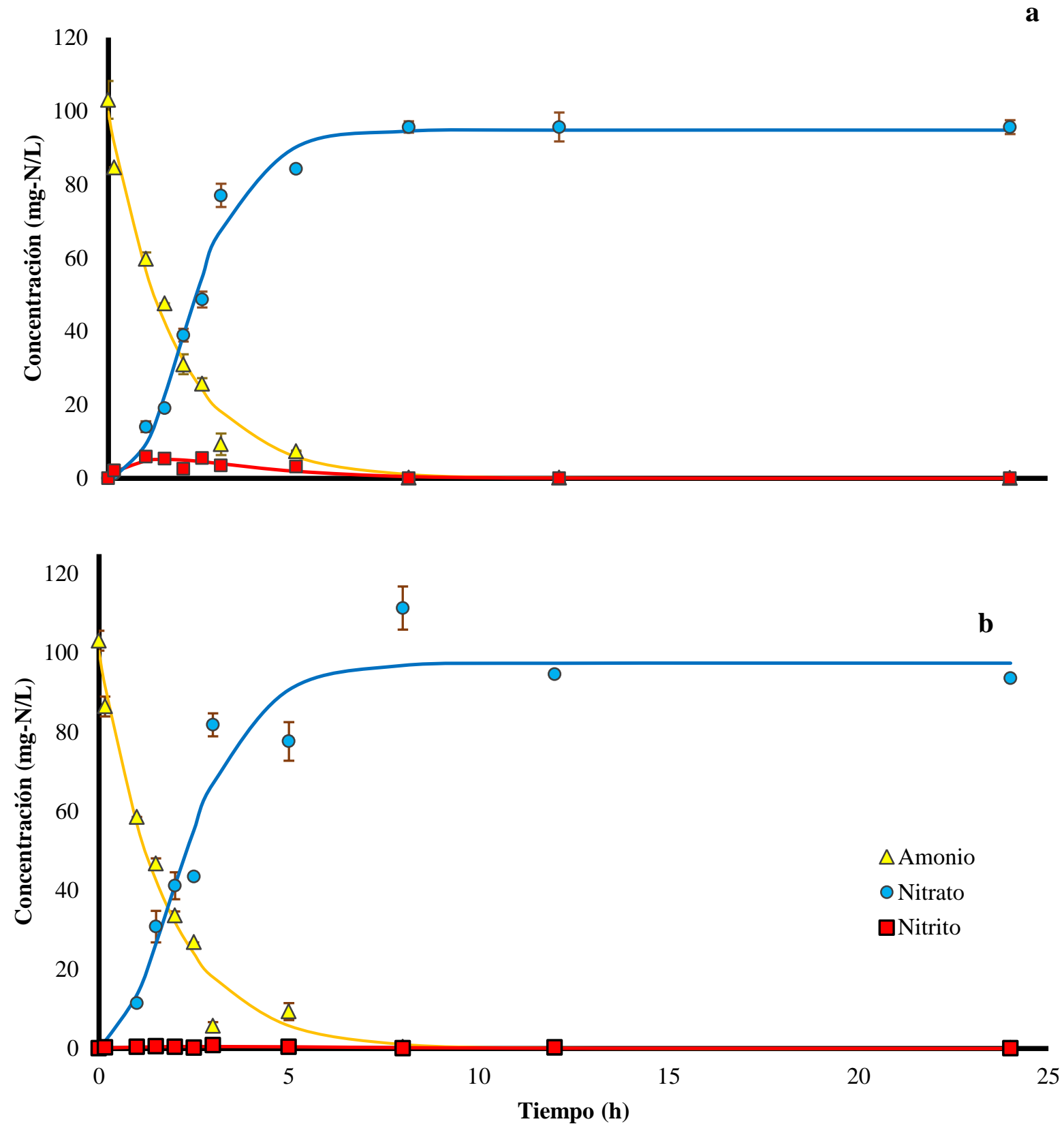

Figura 12. Proceso nitrificante en cultivos en lote: (a) control sin ampicilina y (b) con $10 \mathrm{mg} / \mathrm{L}$ de ampicilina. 

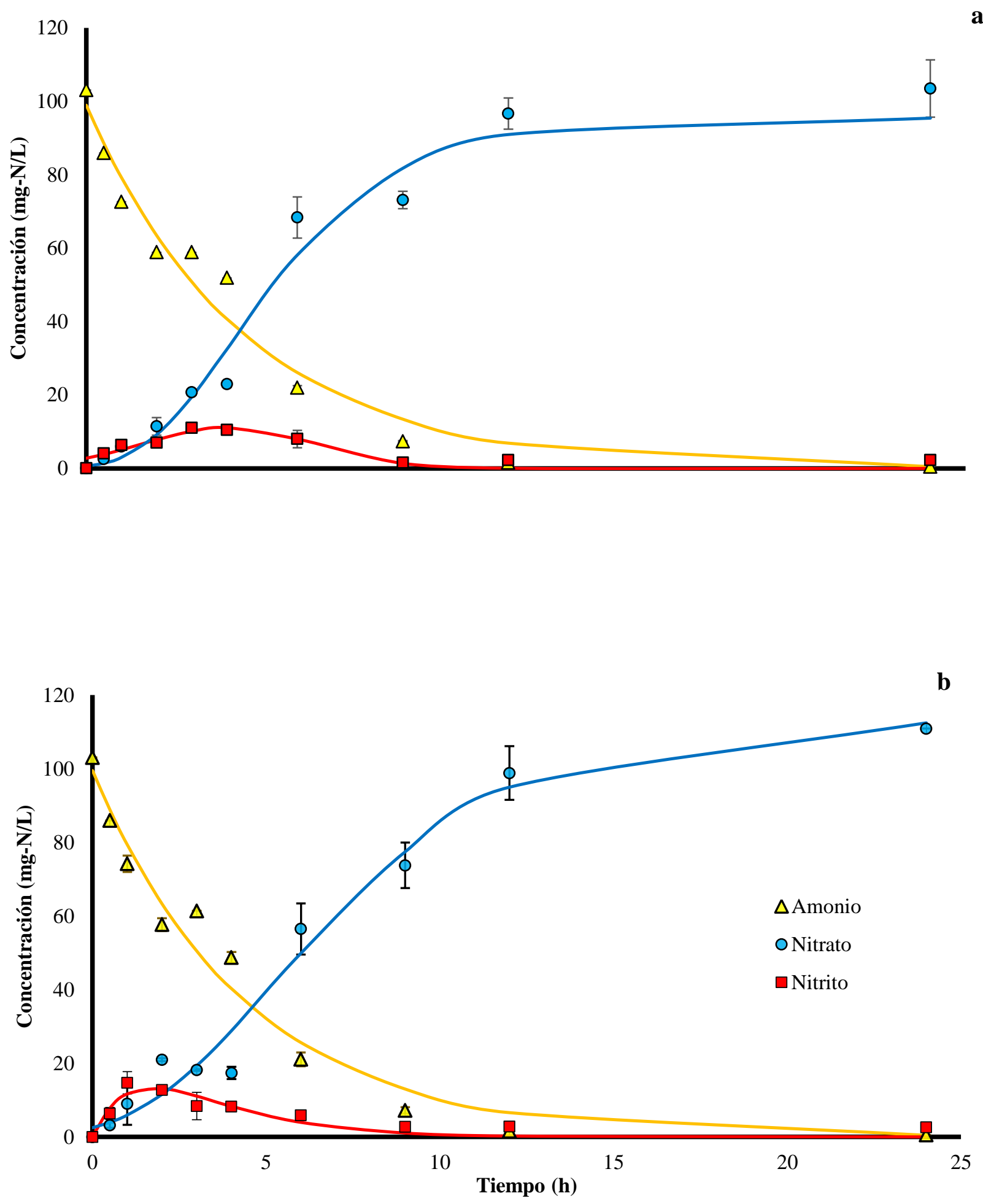

Figura 13. Proceso nitrificante en cultivos en lote: (a) control $\sin$ ampicilina y (b) con $25 \mathrm{mg} / \mathrm{L}$ de ampicilina. 

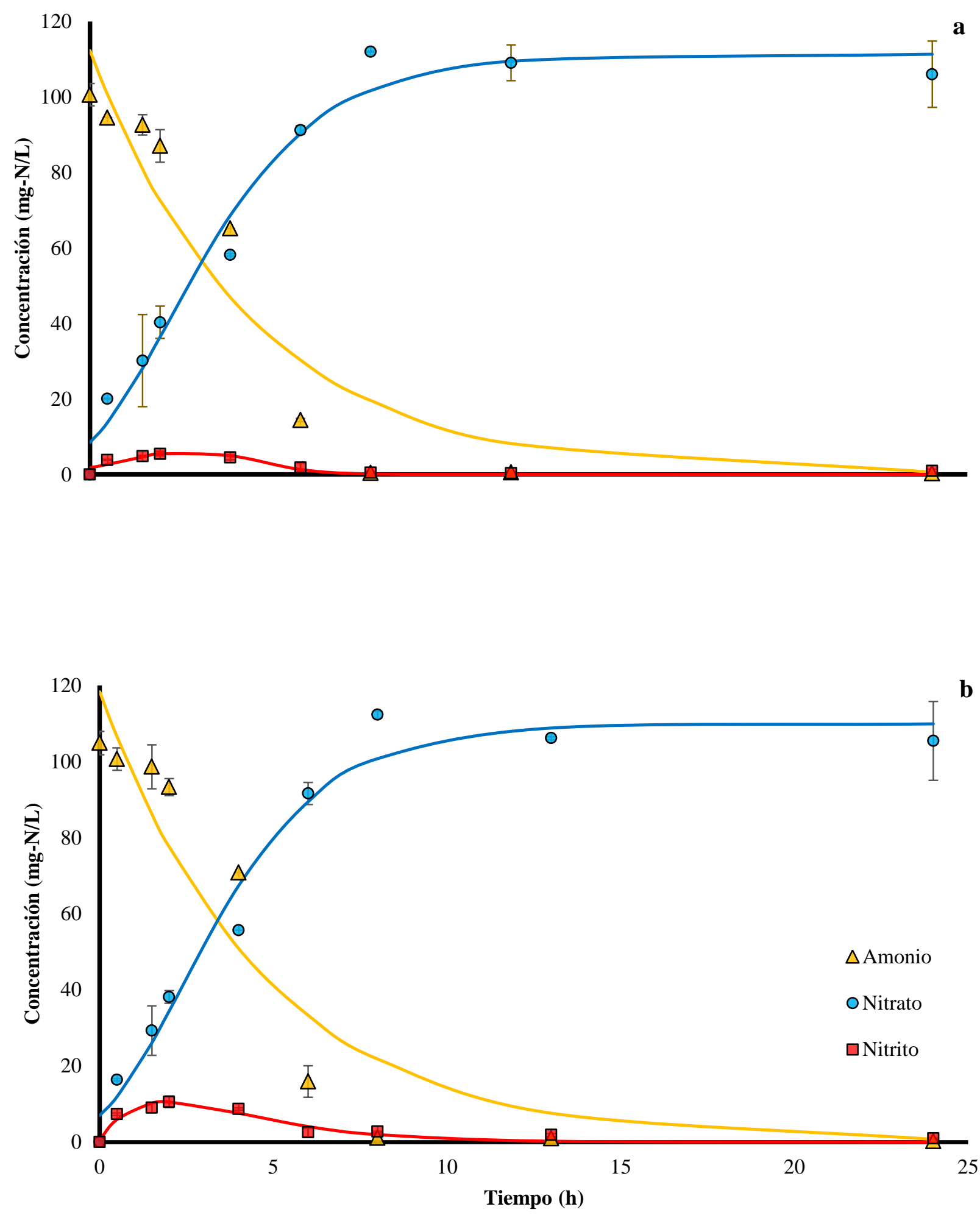

Figura 14. Proceso nitrificante en cultivos en lote: (a) control sin ampicilina y (b) con $50 \mathrm{mg} / \mathrm{L}$ de ampicilina. 
En las figuras de los perfiles cinéticos obtenidos a distintas concentraciones (Figs. 12, 13 y 14), no se aprecian diferencias en los cultivos sin y con adición de ampicilina. De la misma forma, los resultados encontrados a las diferentes concentraciones de ampicilina empleadas fueron muy similares entre sí. Lo anterior indica que la presencia de ampicilina hasta 50 $\mathrm{mg} / \mathrm{L}$ y bajo las condiciones experimentales utilizadas, no alteró el proceso nitrificante.

Los valores de eficiencia en el consumo de amonio, rendimientos de formación de nitrito y nitrato, así como velocidades específicas de consumo de amonio y formación de nitrato se presentan en la Tabla 5. En todos los cultivos en lote, sin importar la presencia o no de ampicilina, se obtuvieron altas eficiencias, altos rendimientos de nitrato y rendimientos de nitrito cercanos a cero (promedios: $\mathrm{E}_{\mathrm{NH} 4+}=99.7 \pm 4.2 \%, \mathrm{YNO}_{3}{ }^{-}: 1.0 \pm 0.1 \mathrm{mg} \mathrm{N} / \mathrm{mg} \mathrm{N}-$ $\mathrm{NH}_{4}{ }^{+}$consumido, $\mathrm{YNO}_{2}{ }^{-}: 0.0 \pm 0.0 \mathrm{mg} \mathrm{N} / \mathrm{mg} \mathrm{N}-\mathrm{NH}_{4}{ }^{+}$consumido). Esto muestra que la ampicilina no tuvo efecto sobre la fisiología de la nitrificación ya que no modificó ni los valores de eficiencia ni los de rendimientos. No se detectó diferencia significativa entre las concentraciones de biomasa inicial $(320.1 \pm 5.1 \mathrm{mg}$-proteína/L) y final $(319.9 \pm 5.3 \mathrm{mg}$ proteína/L). Estos resultados muestran que el proceso fue principalmente desasimilativo, favoreciendo la formación de energía por un proceso nitrificante catabólico y la formación de biomasa fue mínima. En general, se observó también una similitud en las velocidades específicas para una misma concentración de ampicilina entre los cultivos control y los cultivos con antibiótico, esto muestra que la ampicilina tampoco provocó un efecto inhibitorio en la nitrificación. En el caso del ensayo con $25 \mathrm{mg} / \mathrm{L}$ de ampicilina, se advierte una diferencia en cuanto a las velocidades específicas de producción de nitrato (Tabla 5) entre el control $\left(\mathrm{Q}_{\mathrm{NO} 3}=0.032 \pm 0.007 \mathrm{mg} \mathrm{N}-\mathrm{NO}_{3}{ }^{-} / \mathrm{mg}\right.$ proteína $\bullet$ h $)$ y el cultivo en lote con antibiótico $\left(\mathrm{Q}_{\mathrm{NO} 3}=0.025 \pm 0.005 \mathrm{mg} \mathrm{N}-\mathrm{NO}_{3}{ }^{-} / \mathrm{mg}\right.$ proteína $\left.\bullet h\right)$. A fin de discernir si hubo una disminución significativa en la velocidad de producción de nitrato a consecuencia de la adición de antibiótico a esta concentración, se realizó la prueba t de student para muestras independientes. Los datos no dieron evidencia suficiente para rechazar la hipótesis nula de igualdad de medias entre sin y con $25 \mathrm{mg} / \mathrm{L}$ de ampicilina $(\mathrm{t}=-0.019 ; \mathrm{gl}: 18 ; \mathrm{p}>0.05)$. La conclusión es la misma para pruebas de t de estudent para $10 \mathrm{mg} / \mathrm{L}$ ( $\mathrm{t}=-0.086 ; \mathrm{gl}: 20 ; \mathrm{p}>$ 0.05) y $50 \mathrm{mg} / \mathrm{L}(\mathrm{t}=-0.067$; gl: 16; p > 0.05) (Programa PASW Statistics for Windows, versión 18.0). 
Tabla 5. Ensayos sin y con ampicilina: eficiencias, rendimientos y velocidades específicas de la nitrificación en cultivos en lote.

\begin{tabular}{|c|c|c|c|c|c|}
\hline $\begin{array}{l}\text { Ampicilina } \\
(\mathrm{mg} / \mathrm{L})\end{array}$ & $\mathrm{E}_{\mathrm{NH} 4+}$ & $\mathrm{Y}_{\mathrm{NO}_{2}}^{-}$ & $\mathrm{Y}_{\mathrm{NO}_{3}}^{-}$ & $\mathrm{Q}_{\mathrm{NH} 4}$ & $\mathrm{Q}_{\mathrm{NO} 3}$ \\
\hline Control (10) & $99.9 \pm 4.9$ & $0.0 \pm 0.0$ & $1.0 \pm 0.1$ & $0.060 \pm 0.012$ & $0.074 \pm 0.010$ \\
\hline 10 & $99.9 \pm 4.9$ & $0.0 \pm 0.0$ & $0.9 \pm 0.1$ & $0.060 \pm 0.013$ & $0.079 \pm 0.011$ \\
\hline Control (25) & $99.5 \pm 4.9$ & $0.0 \pm 0.0$ & $1.0 \pm 0.1$ & $0.036 \pm 0.005$ & $0.032 \pm 0.007$ \\
\hline 25 & $99.5 \pm 4.9$ & $0.0 \pm 0.0$ & $1.1 \pm 0.1$ & $0.037 \pm 0.005$ & $0.025 \pm 0.005$ \\
\hline Control (50) & $99.7 \pm 2.9$ & $0.0 \pm 0.0$ & $1.1 \pm 0.1$ & $0.041 \pm 0.007$ & $0.043 \pm 0.004$ \\
\hline 50 & $99.8 \pm 2.9$ & $0.0 \pm 0.0$ & $1.0 \pm 0.1$ & $0.044 \pm 0.007$ & $0.044 \pm 0.003$ \\
\hline $\begin{array}{l}\text { Promedio de } \\
\text { Controles }\end{array}$ & $99.7 \pm 4.2$ & $0.0 \pm 0.0$ & $1.0 \pm 0.1$ & $0.046 \pm 0.008$ & $0.049 \pm 0.007$ \\
\hline $\begin{array}{l}\text { Eficiencia }\left(\mathrm{E}_{\mathrm{NH}}\right. \\
\text { Velocidad espe }\end{array}$ & $\begin{array}{l}\% \text {. Rendimie } \\
\text { (Q): } \mathrm{mg}-\mathrm{N} / \mathrm{r}\end{array}$ & $\begin{array}{l}\mathrm{o}(\mathrm{Y}): \mathrm{mg} \mathrm{N} / \\
\text { proteína } \bullet \mathrm{h}\end{array}$ & $\mathrm{N}-\mathrm{NH}_{4}{ }^{+} \mathrm{co}$ & & \\
\hline
\end{tabular}

Una gran gama de compuestos orgánicos, tales como hidrocarburos de uno a cuatro carbonos, compuestos acetilénicos, compuestos con azufre como pesticidas, fungicidas, disulfuro de carbono, guaniltiourea, aliltiourea, compuestos heterocíclicos, etc. han sido reportados como inhibidores de la nitrificación, disminuyendo las velocidades de la amonio y nitrito oxidación (Keener y Arp, 1994; McCarty, 1999; Sayavedra-Soto et al., 2010; Martínez-Hernández et al., 2011). Se ha reportado que la nitrificación es el proceso biológico de eliminación de nitrógeno de aguas residuales más sensible al efecto inhibitorio de la materia orgánica (Gomez y Lema, 2000; Carrera et al., 2004; Geets et al., 2006; Gajewska et al., 2015). En general se puede decir que falta mucho por hacer en cuanto a estudios del efecto de los antibióticos sobre la nitrificación y en el caso de los betalactámicos, éstos no son la excepción. El efecto que pueda tener un antibiótico sobre el proceso nitrificante depende del compuesto que se trate, y también de las condiciones de experimentación, por ejemplo concentración del compuesto, presencia de otros antibióticos, tiempo de exposición del lodo al antibiótico, etc. (Gomez et al., 1996; Campos et al., 2001; Kümmerer, 2009a, 2009b; Amorim et al., 2014). En el trabajo de Gómez et al. (1996) con concentraciones hasta de $250 \mathrm{mg} / \mathrm{L}$ de ampicilina y un tiempo de $80 \mathrm{~h}$, no se observaron efectos ni sobre la producción de biomasa ni sobre la producción de nitrato por un lodo 
nitrificante en cultivos en lote. Por lo tanto, los resultados obtenidos en el presente estudio coinciden en parte con los presentados por Gómez et al. (1996). Sin embargo, cabe destacar que en este trabajo, los autores se enfocaron al estudio del proceso anabólico reportando tasas específicas de crecimiento celular del lodo nitrificante a diferentes concentraciones de antibiótico. En el presente estudio, se evaluó la actividad respiratoria (catabolismo) de un lodo nitrificante en estado estacionario, dando información complementaria a la reportada previamente por Gómez et al. (1996). Estos mismos autores proporcionaron también valores de la velocidad volumétrica de formación de nitrato en ausencia y presencia de ampicilina, única variable de respuesta utilizada para evaluar el proceso catabólico nitrificante responsable de la oxidación de amonio a nitrato. En el presente trabajo, los resultados de eficiencias, rendimientos y velocidades específicas obtenidos en su conjunto, aportan evidencias claras de que hasta $50 \mathrm{mg}$ ampicilina/L no afectó ni la fisiología ni la cinética del proceso respiratorio nitrificante. Es relevante mencionar también que no se probaron concentraciones mayores de ampicilina en este estudio porque el objetivo principal fue evaluar la capacidad del lodo nitrificante para biotransformar la ampicilina y no tanto determinar la concentración mínima inhibitoria de la nitrificación.

La insensibilidad a la ampicilina de las bacterias que componen el lodo nitrificante así como el nulo efecto sobre el proceso nitrificante se puede explicar a través del concepto de tolerancia. De acuerdo a Brauner et al. (2016), la tolerancia es una característica o estrategia de los microorganismos para sobrevivir a la exposición transitoria de una alta concentración de antibiótico y puede ser heredada o adquirida, por ejemplo, al ralentizarse un proceso bacteriano esencial. De esta forma, la tolerancia a los betalactámicos puede ocurrir cuando las bacterias crecen lentamente, como las bacterias AOB y NOB, y por tanto la construcción de su pared bacteriana es también lenta. Como los $\beta$-lactámicos interfieren en la construcción activa de la pared bacteriana, un crecimiento más lento necesitaría de una exposición más prolongada al antibiótico a fin de eliminar la población de bacterias. Es muy probable que también se presenten otros mecanismos que colaboren en la insensibilidad del lodo a la ampicilina, por ejemplo a través de mutaciones en las proteínas de unión al antibiótico, una actividad enzimática sobre el antibiótico ( $\beta$-lactamasas), modificaciones en la permeabilidad de barreras al antibiótico o a través de bombas de eflujo (Neu, 1982; Tuomanen, 1986; Kümmerer, 2009a; Suárez y Gudiol, 2009; Brauner et al., 
2016). Ensayos de mayor duración empleando concentraciones de antibiótico ambientalmente representativas (exposición crónica) podrían complementar los ensayos en lote de corta duración y de altas concentraciones (concentración aguda) como los efectuados en este trabajo (Roose-Amsaleg y Laverman, 2016).

\subsection{Procesos de eliminación de ampicilina}

Para cada concentración inicial de ampicilina ensayada en los cultivos en lote, se realizaron cinéticas de eliminación de ampicilina bajo diferentes condiciones experimentales con el fin de distinguir los diferentes procesos involucrados en la eliminación del antibiótico: A) Ensayos abióticos sin biomasa para dar seguimiento a la eliminación por procesos físicoquímicos (hidrólisis, reacción química con los componentes del medio y adsorción en la unidad experimental); B) Ensayos de adsorción con biomasa sin oxígeno para evaluar la eliminación de ampicilina por adsorción en el lodo (biosorción) mediante la comparación de los resultados de los ensayos B y A; C) Cultivos nitrificantes con biomasa y oxígeno para evaluar la eliminación de ampicilina por biotransformación mediante la comparación de los resultados de los ensayos $\mathrm{C}$ y $\mathrm{B}$.

\subsubsection{Cinéticas de eliminación a $10 \mathrm{mg} / \mathrm{L}$ de ampicilina}

A $10 \mathrm{mg} / \mathrm{L}$ de ampicilina, la eliminación abiótica del antibiótico en los ensayos en lote sin biomasa fue de $16.1 \%$ en los primeros 30 minutos y se mantuvo en ese valor hasta las $24 \mathrm{~h}$ (Fig. 15). Esto puede deberse a procesos físico-químicos como hidrólisis, reacción química con los componentes del medio o adsorción en la unidad experimental (Deshpande et al., 2004; Li y Zhang, 2010; Mitchel et al., 2014). 


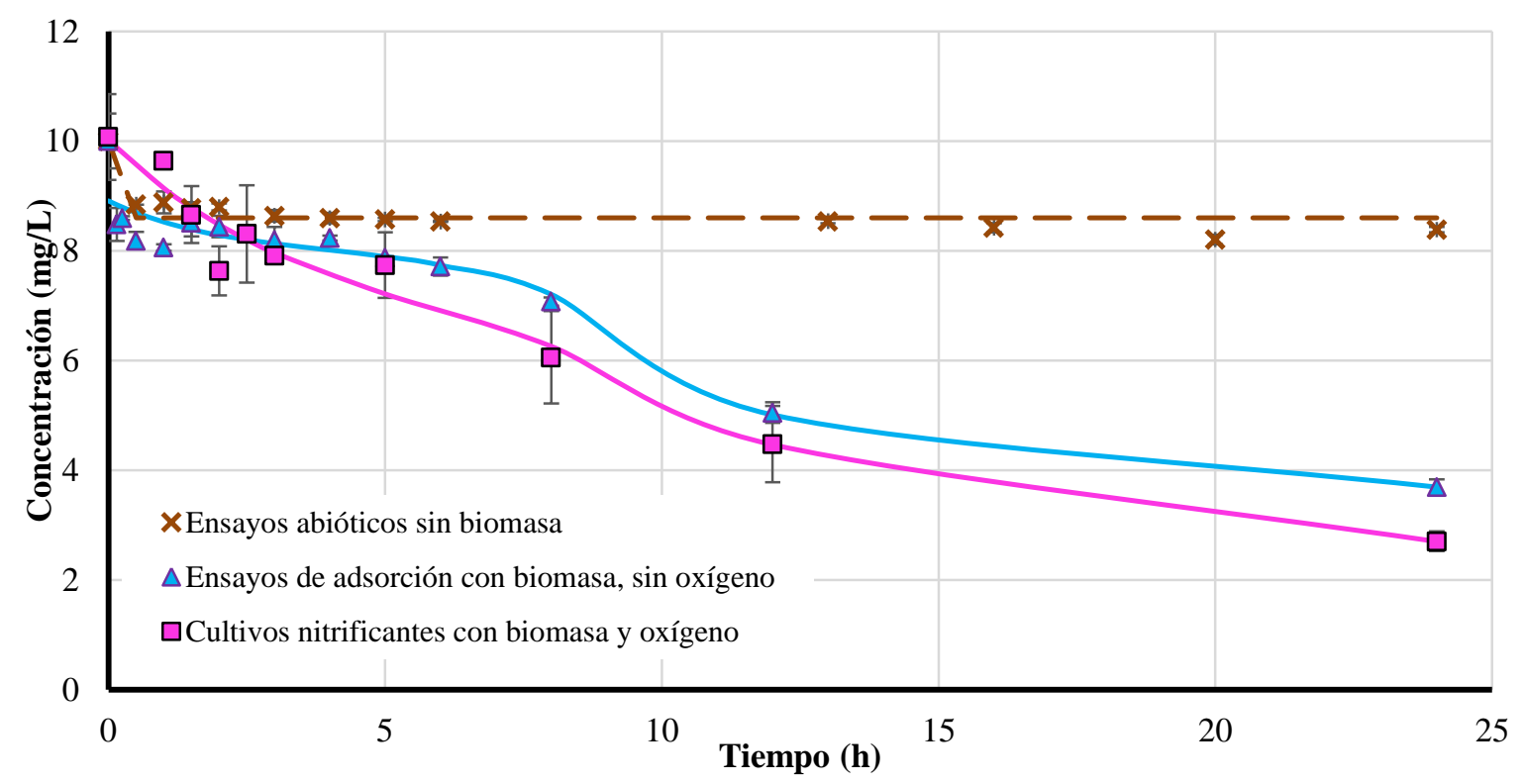

Figura 15. Cinéticas de eliminación a $10 \mathrm{mg} / \mathrm{L}$ de ampicilina en ensayos abióticos, de adsorción y cultivos nitrificantes.

Cuando se inocularon los cultivos en lote con biomasa nitrificante bajo las mismas condiciones experimentales pero sin oxígeno, la actividad biológica aerobia se detuvo, sin embargo el porcentaje de eliminación de ampicilina aumentó a $63.1 \%$ a las 24 h de cultivo, mostrando la capacidad del lodo nitrificante para eliminar ampicilina a través de adsorción. De acuerdo al estudio realizado por Hamon et al. (2014), de las tres técnicas empleadas para inhibir la actividad metabólica de lodos (térmica, química y purga con gas), la que mejor preserva la estructura celular, manteniendo de esta forma las propiedades de adsorción de la biomasa microbiana en un lodo aerobio, es la de purga con gas nitrógeno. Utilizando esta técnica en la serie de ensayos de adsorción (con 10, 25 y $50 \mathrm{mg} / \mathrm{L} \mathrm{de}$ ampicilina y $103.1 \mathrm{mg} / \mathrm{L}$ de $\mathrm{N}_{-} \mathrm{NH}_{4}{ }^{+}$), se verificó que no hubo actividad biológica nitrificante, obteniéndose después de 24 h, una concentración final de amonio de $101.4 \pm$ $2.3 \mathrm{mg} / \mathrm{L}$ de $\mathrm{N}^{-\mathrm{NH}_{4}}{ }^{+}$(98.4\% del inicial), $0.5 \pm 0.2 \mathrm{mg} / \mathrm{L}$ de $\mathrm{N}^{-\mathrm{NO}_{2}}{ }^{-}$y de nitrato de $0.07 \pm$ $0.1 \mathrm{mg} / \mathrm{L}$ de $\mathrm{N}-\mathrm{NO}_{3}{ }^{-}$.

Posteriormente, se observó que en los cultivos nitrificantes con biomasa y oxígeno, el porcentaje de eliminación de ampicilina fue de $73.1 \%$, indicando que una parte fue consumida por actividad biológica. Se puede decir que en los cultivos nitrificantes en lote 
con $10 \mathrm{mg} / \mathrm{L}$ de ampicilina el principal proceso de eliminación del antibiótico fue el proceso de adsorción sobre el lodo.

\subsubsection{Cinéticas de eliminación a $25 \mathrm{mg} / \mathrm{L}$ de ampicilina}

Al aumentar la concentración inicial de ampicilina adicionada en los cultivos en lote a 25 mg/L (Fig. 16), se observó también una pérdida del antibiótico por procesos abióticos de alrededor de $16.5 \%$ a las 24 h. De la misma forma, también se presentó un incremento en el porcentaje de eliminación de 16.5 a 39.7\% a través de procesos de biosorción. Sin embargo, a diferencia de los ensayos con $10 \mathrm{mg} / \mathrm{L}$ de ampicilina, en presencia de biomasa y oxígeno en los cultivos, el porcentaje aumentó en una mayor proporción, hasta 65.9\%, mostrando un aumento en la capacidad de la biomasa para consumir ampicilina vía metabólica.

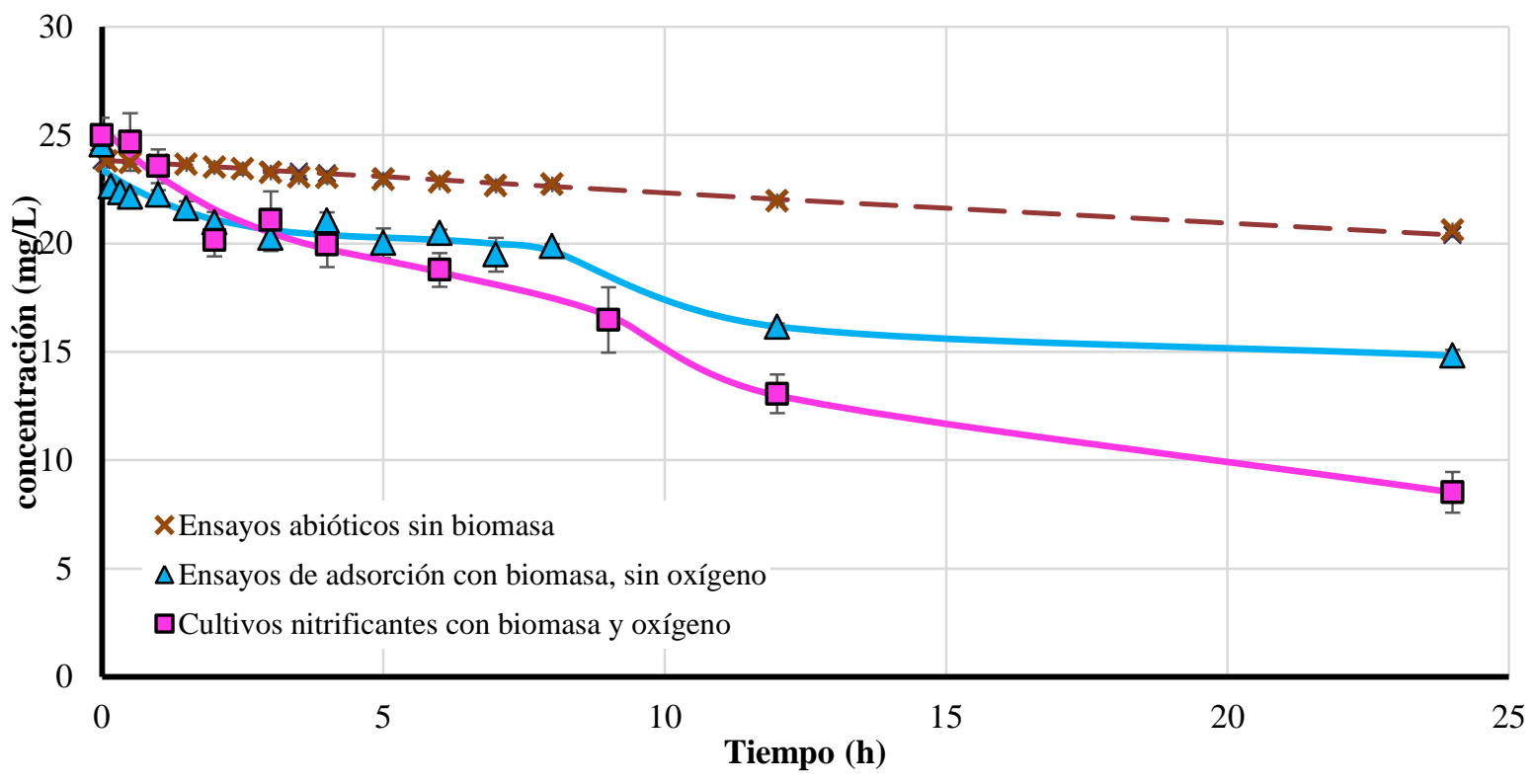

Figura 16. Cinéticas de eliminación a $25 \mathrm{mg} / \mathrm{L}$ de ampicilina en ensayos abióticos, de adsorción y cultivos nitrificantes. 


\subsubsection{Cinéticas de eliminación a $50 \mathrm{mg} / \mathrm{L}$ de ampicilina}

De manera similar a las concentraciones anteriores, a $50 \mathrm{mg} / \mathrm{L}$ de ampicilina, se determinó que el antibiótico fue eliminado del cultivo de $24 \mathrm{~h}$ por procesos físico-químicos (16.0\%), de biosorción (42.6\%) y de biotransformación (72.4\%) (Fig. 17). Se observó que al aumentar la concentración a $50 \mathrm{mg} / \mathrm{L}$ de ampicilina, la contribución de la actividad biológica en la eliminación de ampicilina siguió siendo significativa.

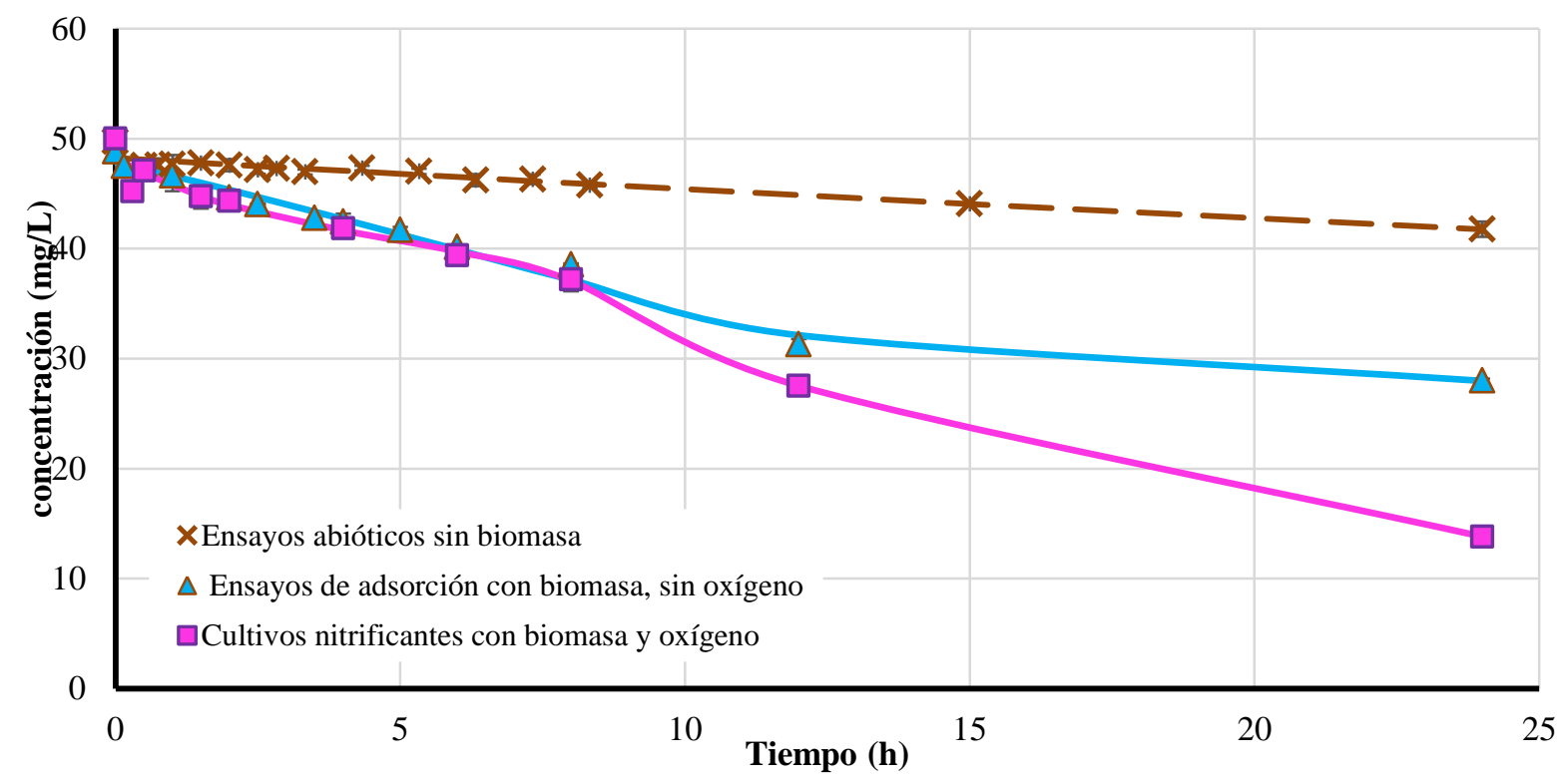

Figura 17. Cinéticas de eliminación a $50 \mathrm{mg} / \mathrm{L}$ de ampicilina en ensayos abióticos, de adsorción y cultivos nitrificantes.

\subsubsection{Resumen de procesos de eliminación de ampicilina}

La contribución de cada proceso a la eliminación de ampicilina en los cultivos nitrificantes se estimó por diferencia entre los resultados de los ensayos A, B y C. Los resultados se presentan en la Tabla 6 y la Fig. 18. 


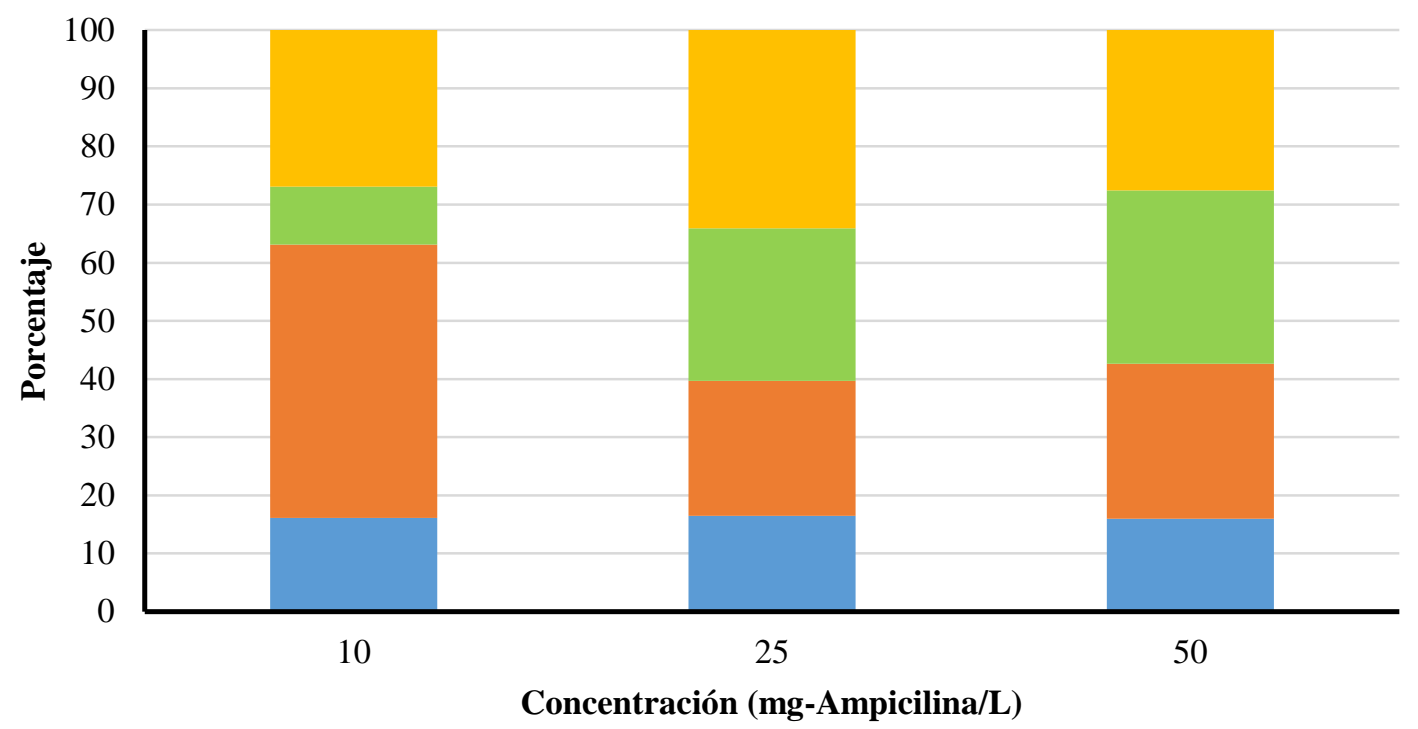

घbiótico $\quad$ Biosorción $\quad$ Biotransformación $\quad$ Remanente

Figura 18. Contribución de los procesos abióticos, de biosorción y biotransformación en la eliminación de ampicilina en cultivos nitrificantes en lote.

Tabla 6. Eliminación de ampicilina por procesos físico-químicos (abióticos), de adsorción en el lodo y biotransformación.

\begin{tabular}{llllllll}
\hline Ampicilina & & & & B-A & C-B & Remanente & Remanente \\
\hline $\mathrm{mg} / \mathrm{L}$ & $\mathrm{A}(\%)$ & $\mathrm{B}(\%)$ & $\mathrm{C}(\%)$ & $\begin{array}{l}\text { Biosorción } \\
(\%)\end{array}$ & $\begin{array}{l}\text { Biotrans- } \\
\text { formación }(\%)\end{array}$ & $\begin{array}{l}(\mathrm{mg} / \mathrm{L} \mathrm{de} \\
\text { ampicilina })\end{array}$ & $(\%)$ \\
\hline & & & & & & \\
\hline 10 & $16.1 \pm 0.8$ & $63.1 \pm 2.4$ & $73.1 \pm 3.5$ & $47.0 \pm 2.2$ & $10.0 \pm 5.9$ & $2.7 \pm 0.2$ & $26.9 \pm 3.9$ \\
\hline 25 & $16.5 \pm 1.2$ & $39.7 \pm 2.0$ & $65.9 \pm 4.3$ & $23.2 \pm 1.2$ & $26.2 \pm 6.3$ & $8.5 \pm 0.9$ & $34.1 \pm 4.1$ \\
\hline 50 & $16.0 \pm 0.7$ & $42.6 \pm 1.8$ & $72.4 \pm 3.2$ & $26.6 \pm 2.5$ & $29.8 \pm 5.0$ & $13.8 \pm 0.2$ & $27.6 \pm 0.6$
\end{tabular}

A: Ensayos abióticos sin biomasa (procesos físico-químicos); B: Ensayos con biomasa sin oxígeno (procesos físicoquímicos + biosorción); C: Cultivos nitrificantes con biomasa y oxígeno (procesos físico-químicos + biosorción + biotransformación). Cálculo de porcentajes de la contribución de cada proceso en la eliminación de ampicilina: A: abióticos, B-A: biosorción y C-B: biotransformación.

Los porcentajes de eliminación fueron determinados a las $24 \mathrm{~h}$ de cultivo.

Se puede apreciar que la eliminación del antibiótico fue efectuada principalmente a través de los procesos de adsorción y biotransformación y en menor medida a través de procesos físico-químicos. Varios trabajos han reportado que los dos mecanismos principales 
responsables de la eliminación de antibióticos en procesos de lodos activados en plantas de tratamiento de aguas residuales son la adsorción en el lodo y la biodegradación (Batt et al., 2007; Li y Zhang 2010; Michael et al., 2013). Así por ejemplo Pérez et al. (2005) estudiaron la biodegradación aerobia de los antibióticos sulfametazina, sulfametoxazol, sulfatiazol y trimetoprima en las aguas de drenaje procedentes de cuatro etapas de tratamiento (tratamiento primario, lodos activados, proceso de nitrificación, y desinfección de las aguas tratadas) de una planta municipal de Amherst, Nueva York, EUA. Para su estudio usaron reactores en lote aireados y monitoreados durante $54 \mathrm{~d}$. Encontraron que las tasas más altas de degradación se obtuvieron en las aguas de desecho procedentes del tratamiento de lodos activados (concentraciones relativas de las sulfonamidas abajo del 7\% para el día 10). La trimetoprima presentó alta resistencia a la degradación microbiana en las aguas procedentes del tratamiento primario y del tratamiento con lodos activados, sin embargo su degradación se completó en tan solo 3 d en las aguas del proceso de nitrificación. Los reactores control (biológicamente inactivados con azida de sodio) no mostraron procesos de eliminación abiótica, lo cual puede atribuirse a los bajos valores del $\log \mathrm{K}_{\mathrm{ow}}(-0.07$ a 0.91$)$ y de presión de vapor (0.036-2.35 x $10^{-9}$ torr) de estos compuestos. Marcelino et al. (2016) al estudiar la amoxicilina en las aguas de desecho de una industria farmacéutica productora de antibióticos en Brasil evaluaron la biodegradación aerobia y anaerobia, la adsorción al lodo de este antibiótico. Para la parte aerobia se usó lodo activado de una planta municipal. Para la parte anaerobia se usó lodo de un reactor UASB y nitrógeno como gas de purga. En ambos casos se empleó $0.6 \mathrm{~g} / \mathrm{L}$ de biomasa. La concentración inicial de amoxicilina en las aguas de desecho fue de 120 mg/L y la duración de las pruebas de biodegradación fue de 28 d. Los autores encontraron que a los 12 días de tratamiento aerobio ya se había eliminado alrededor de $80 \%$ de la ampicilina inicial de las aguas de desecho y cerca del $50 \%$ a través del tratamiento anaerobio. Sin embargo, las pruebas de desorción con el lodo aerobio, mostraron que en realidad 54\% de la amoxicilina inicial presente en el reactor estaba adsorbida al lodo y no había sido degradada por microorganismos. Solamente $26 \%$ fue biodegradada. No se realizaron pruebas de desorción para el lodo del tratamiento anaerobio.

En el presente estudio, es importante señalar que con el incremento en la concentración de antibiótico, hubo una mayor participación del lodo a través del proceso de 
biotransformación para eliminar la ampicilina (Fig. 18). Como se puede observar en la Tabla 7, en los cultivos nitrificantes con biomasa y oxígeno, no se observaron diferencias significativas en las eficiencias finales de eliminación de ampicilina (promedio de $\mathrm{E}_{\mathrm{amp}}=$ $70.5 \pm 2.5 \%, \mathrm{CV}=5.6 \%$ ), pero sí en la velocidad específica ( $\left.\mathrm{Q}_{\mathrm{amp}}, \mathrm{CV}=59.5 \%\right)$, la cual aumentó con la concentración inicial de antibiótico. Estos resultados muestran que el lodo fue capaz de oxidar amonio a nitrato por nitrificación y eliminar ampicilina por vía biológica. Se puede asociar este aumento en la velocidad específica de eliminación de ampicilina con el aumento de la actividad biológica en su consumo.

Tabla 7. Eficiencias y velocidades específicas de eliminación de ampicilina en cultivos en lote.

\begin{tabular}{ccc}
\hline $\begin{array}{c}\text { Ampicilina } \\
(\mathrm{mg} / \mathrm{L})\end{array}$ & $\mathrm{E}_{\text {amp }}$ & $\mathrm{Q}_{\text {amp }}$ \\
\hline 10 & $73.1 \pm 0.2$ & $0.0013 \pm 0.0002$ \\
25 & $65.9 \pm 5.4$ & $0.0029 \pm 0.0003$ \\
\hline 50 & $72.4 \pm 2.0$ & $0.0049 \pm 0.0004$ \\
\hline
\end{tabular}

Eficiencia $\left(\mathrm{E}_{\mathrm{amp}}\right)$ : \%. Velocidad específica $\left(\mathrm{Q}_{\mathrm{amp}}\right)$ : $\mathrm{mg} / \mathrm{mg}$ proteína•h.

Dado que no se observó alteración alguna del proceso nitrificante en presencia de ampicilina, se puede descartar la participación de las bacterias nitrificantes del lodo en la biotransformación de la ampicilina. Cabe mencionar que el lodo empleado como fuente de inóculo fue caracterizado en un estudio previo en cuanto a taxa integrantes (Silva et al., 2014). De esta forma, se identificaron siete miembros de las Betaproteobacterias próximos a las especies: Nitrosomonas europaea, $N$. halophila, $N$. oligotropha y una bacteria amonio oxidante no cultivable (estas cuatro son AOB), así como Variovorax paradoxus, Thauera mechernichensis e Hydrogenophaga bisanensis. En las Alfaproteobacterias, se identificó a una especie relacionada al género Nitrobacter y en el phylum Nitrospira a Nitrospira sp. (estas dos especies pertenecientes a las NOB). En cuanto a los organismos heterótrofos identificados, se tiene a Variovorax paradoxus y Thauera mechernichensis. V. paradoxus es una bacteria nitrato reductora con capacidad para oxidar compuestos fenólicos como fuente única de carbono y energía mientras que $T$. mechernichensis es una bacteria desnitrificante heterótrofa aerobia que puede utilizar el benzoato, parahidroxibenzoato, leucina y fenilacetato como fuente única de carbono. Las bacterias del género Thauera además tienen la capacidad para degradar compuestos aromáticos como fenol y cresoles 
(Silva et al., 2014). Aunque la composición microbiológica del lodo utilizado en el presente estudio haya muy probablemente cambiado respecto a la reportada por Silva et al. (2014), estos resultados previos indican que puede haber microorganismos heterótrofos en el consorcio utilizado, los cuales pudieran estar involucrados en la biotransformación de la ampicilina. Sin embargo, queda claro que son necesarios más estudios al respecto para aclarar este punto.

Al medir el carbono orgánico total (COT) al inicio y final de los ensayos en lote, no se observó disminución en el COT, así para 10, 25 y 50 mg/L de ampicilina añadida al inicio de los ensayos, se pudo detectar al final $15.5 \pm 0.5,24.1 \pm 1.1$ y $51.4 \pm 2.2 \mathrm{mg} / \mathrm{L}$ de COT, respectivamente. Con lo anterior se puede concluir que si bien el lodo nitrificante transformó la ampicilina, el antibiótico no se mineralizó hasta $\mathrm{CO}_{2}$. Además, en las mediciones efectuadas por cromatografía de líquidos (HPLC) al dar seguimiento a la ampicilina añadida inicialmente, no se observaron picos adicionales en los cromatogramas. Esto indica que los posibles productos derivados de la transformación del antibiótico no pudieron ser detectados bajo las condiciones de análisis utilizadas en el equipo de HPLC. Es importante conocer los derivados resultantes de la biotransformación microbiana de antibióticos ya que de esta forma se puede evaluar el impacto que tienen estos compuestos sobre los ecosistemas. En vista de los múltiples derivados a los que pueden dar lugar los betalactámicos (Deshpande et al., 2004) y a fin de identificar el compuesto o los compuestos que origina la ampicilina en particular (Li et al., 2014), sería necesario realizar otro estudio con este objetivo.

Para los tres cultivos nitrificantes en lote con 10, 25 y $50 \mathrm{mg} / \mathrm{L}$ de ampicilina, se observó un remanente de antibiótico al final del ensayo (24 h) (Fig. 18, Tabla 6). Con el fin de verificar si la permanencia en el cultivo del antibiótico fue por limitación en oxígeno disuelto en el cultivo, se dio seguimiento a las concentraciones en OD y ampicilina en ensayos en lote de mayor duración (94 h) y con $25 \mathrm{mg} / \mathrm{L}$ de ampicilina (Tabla 8). Los resultados muestran que se presentó tanto un remanente de antibiótico como de oxígeno hasta después de 94 h de cultivo. Después de 24 h, la baja disponibilidad de oxígeno en el cultivo pudo causar una disminución en la velocidad de eliminación del antibiótico. 
Tabla 8. Concentración de oxígeno disuelto (OD) y ampicilina en un cultivo nitrificante con $25 \mathrm{mg} / \mathrm{L}$ de ampicilina.

\begin{tabular}{cccc}
\hline $\begin{array}{c}\text { Tiempo } \\
(\mathrm{h})\end{array}$ & $\begin{array}{c}\text { Concentración de OD } \\
\left(\mathrm{mg} \mathrm{O}_{2} / \mathrm{L}\right)\end{array}$ & $\begin{array}{c}\text { Concentración de } \\
\text { ampicilina }(\mathrm{mg} / \mathrm{L})\end{array}$ & $\begin{array}{c}\text { Remanente de ampicilina } \\
(\%)\end{array}$ \\
\hline 0 & $6.4 \pm 0.2$ & $25.0 \pm 0.3$ & $100.0 \pm 2.0$ \\
\hline 24 & $2.1 \pm 0.1$ & $8.5 \pm 0.9$ & $34.1 \pm 4.1$ \\
\hline 48 & $1.9 \pm 0.1$ & $7.7 \pm 0.1$ & $31.1 \pm 0.5$ \\
\hline 94 & $1.9 \pm 0.3$ & $5.2 \pm 0.1$ & $20.7 \pm 0.2$ \\
\hline
\end{tabular}

De acuerdo a la reacción global de la nitrificación que incluye la formación de biomasa (ecuación 5), son necesarios $1.83 \mathrm{~mol}$ de $\mathrm{O}_{2}$ por mol de amonio de forma que se necesitan $4.18 \mathrm{~g}$ de $\mathrm{O}_{2} / \mathrm{g}$ de $\mathrm{N}_{-} \mathrm{NH}_{4}{ }^{+}\left(58.52 \mathrm{~g} \mathrm{O}_{2} / 14.01 \mathrm{~g} \mathrm{~N}^{-N_{4}}{ }_{4}^{+}\right)$. En los cultivos en lote, se utilizaron $0.01031 \mathrm{~g}$ de $\mathrm{N}_{-} \mathrm{NH}_{4}{ }^{+}$en cada botella por lo que empleando la relación estequiométrica, serían necesarios $43.08 \mathrm{mg}$ de $\mathrm{O}_{2}$ para esa cantidad de $\mathrm{N}_{-} \mathrm{NH}_{4}{ }^{+}$. La concentración de oxígeno disuelto en la parte líquida fue de $6.4 \pm 0.2 \mathrm{mg} / \mathrm{L}$, es decir que había $0.64 \mathrm{mg}$ de $\mathrm{O}_{2}\left(25{ }^{\circ} \mathrm{C}, 0.763 \mathrm{~atm}, 0.35 \%\right.$ de salinidad $)$ y en el espacio de cabeza se estimó en $59.84 \mathrm{mg}$ de $\mathrm{O}_{2}\left(\mathrm{PV}=\mathrm{nRT}, \mathrm{P}=0.763 \mathrm{~atm}, \mathrm{~V}=0.060 \mathrm{~L}, \mathrm{R}=0.082 \mathrm{~atm} \mathrm{~L} / \mathrm{mol}{ }^{\circ} \mathrm{K}\right.$, $\mathrm{T}=298.15^{\circ} \mathrm{K}, 32 \mathrm{~g} \mathrm{de}_{2} / \mathrm{mol} \mathrm{de}_{2}$ ), siendo en total $60.48 \mathrm{mg} \mathrm{O}_{2} /$ botella. Es decir que con el oxígeno suministrado al sistema, era posible cubrir la demanda del mismo en la nitrificación y tener teóricamente $17.4 \mathrm{mg}$ de $\mathrm{O}_{2}\left(60.48\right.$ - $\left.43.08 \mathrm{mg} \mathrm{O}_{2}\right)$ disponibles aún en la botella serológica. Los posibles productos sugeridos de la transformación parcial de la ampicilina (alrededor de 20) prácticamente no incorporan oxígeno del medio en sus estructuras (Fig. 2) (Deshpande et al., 2004; Li et al., 2014), por lo que es probable que éste elemento sea requerido más bien en funciones metabólicas esenciales de los organismos presentes en el lodo nitrificante y no para incorporarse en la molécula de ampicilina o en algún derivado. Lo anterior induce a considerar la participación de otros organismos aerobios (distintos de las AOB o NOB) y dependientes del oxígeno para biotransformar la ampicilina, de forma que a partir de $2 \mathrm{mg}$ de $\mathrm{O}_{2} / \mathrm{L}$ y/o un $\mathrm{pH}$ de 5.8 (valor experimental de pH después de 24 h), el consumo biológico fue muy lento. Sin embargo, se requiere más estudios para entender mejor cuáles son los factores que pudieran influir en la recalcitrancia de la ampicilina en los cultivos nitrificantes. 


\section{8.- Conclusiones}

El lodo mostró una respiración nitrificante eficiente y estable tanto en el reactor en continuo fuente de inóculo como en los cultivos control en lote en ausencia de ampicilina con eficiencias de consumo de amonio cercanas al $100 \%$ y rendimientos de nitrato cercanos a 1 . Bajo las condiciones de experimentación y a las concentraciones de ampicilina de 10, 25 y $50 \mathrm{mg} / \mathrm{L}$, no se observó efecto alguno sobre la eficiencia y el rendimiento de formación de nitrato en el proceso nitrificante y tampoco un efecto inhibitorio, ya que no hubo cambios significativos en las velocidades específicas de los procesos amonio y nitrito oxidantes. Los resultados mostraron que hasta $50 \mathrm{mg}$ ampicilina/L no afectó ni la fisiología ni la cinética del proceso respiratorio nitrificante. A las tres concentraciones de ampicilina ensayadas, se eliminó $70.5 \pm 2.5 \%$ del antibiótico en $24 \mathrm{~h}$ a través de procesos físico-químicos, biosorción y biotransformación. El consorcio nitrificante mostró la capacidad metabólica de transformar la ampicilina bajo condiciones aerobias, pero sin llegar a la mineralización completa. Con el incremento en la concentración inicial de antibiótico, hubo una mayor participación del lodo a través del proceso de biotransformación para eliminar la ampicilina y se registró un aumento en la velocidad específica de consumo. Estos resultados muestran que el lodo fue capaz de oxidar amonio a nitrato por nitrificación y eliminar ampicilina por vía biológica. La información generada en este trabajo puede ser útil para entender mejor el papel de los lodos nitrificantes en procesos de tratamiento de aguas en la biotransformación de ampicilina. A las concentraciones trazas de ampicilina encontradas generalmente en las plantas de tratamiento, la nitrificación no sería afectada ni en términos fisiológicos ni cinéticos. Sin embargo, los lodos nitrificantes pueden jugar un papel significativo en la biotransformación de la ampicilina en conjunto con la oxidación de amonio. 
9.- Referencias

1. Acred P., Brown D.M., Turner D.H., Wilson M.J. (1962). Pharmacology and Chemotherapy of Ampicillin a New Broad-Spectrum Penicillin. British Journal of Pharmacology. 18: 356- 69.

2. Ahmed M.B., Zhou J.L., Ngo H.H., Guo W. (2015). Adsorptive removal of antibiotics from water and wastewater: Progress and Challenges. 532: 112-26. DOI: 10.1016/j.scitotenv.2015.05.130

3. Amorim C.L., Maia A.S., Mesquita R.B.R., Rangel A.O.S.S., van Loosdrecht M.C.M., Tiritan M. E., Castro P. M.L. (2014). Performance of aerobic granular sludge in a sequencing batch bioreactor exposed to ofloxacin, norfloxacin and ciprofloxacin. Water Research 50: 101-13. DOI: 10.1016/j.watres.2013.10.043

4. Ampicillin. (2005, Junio 24).Tomado de https://pubchem.ncbi.nlm.nih.gov/compound /ampicillin\#section $=$ Top

5. Atlas R.M., Bartha R. (2008). Ciclos biogeoquímicos: nitrógeno, azufre, fósforo, hierro y otros elementos. En I. Capella (Ed.), Ecología microbiana y Microbiología ambiental (4 $4^{\mathrm{a}}$ ed., pp. 411-22). Madrid, España: Pearson Educación.

6. Batt, A.L., Kim, S., Aga, D.S. (2006). Enhanced Biodegradation of Iopromide and Trimethoprim in Nitrifying Activated Sludge. Environmental Science \& Technology. 40: 7367-73. DOI:10.1021/es060835v

7. Batt A.L., Kim S., Aga D.S. (2007). Comparison of the occurrence of antibiotics in four full-scale wastewater treatment plants with varying designs and operations. Chemosphere. 68: 428-35. DOI: 10.1016/j.chemosphere.2007.01.008

8. Beristain-Cardoso R., Texier A-C., Razo-Flores E., Méndez-Pampín R., Gómez J. (2009). Biotransformation of aromatic compounds from wastewaters containing $N$ and/or $S$, by nitrification/denitrification: a review. Reviews in Environmental Science and Biotechnology. 8: 325-42. DOI 10.1007/s11157-009-9172-0

9. Bernet N., Spérandio M. (2009). Principles of nitrifying processes. En F. J. Cervantes (Ed.), Environmental Technologies to Treat Nitrogen Pollution (pp. 23-31). London, UK: IWA Publishing.

10. Birošová L, Mackulak T., Bodík I., Ryba J., Škubák J., Grabic R. (2014). Pilot study of seasonal ocurrence and distribution of antibiotics and drug resistant bacteria in wastewater treatment plants in Slovakia. Science of the Total Environment. 490: 440-44. DOI:10.1016/j.scitotenv.2014.05.030 
11. Brauner A., Fridman O., Gefen O., Balaban N.Q. (2016). Distinguishing between resistance, tolerance and persistence to antibiotic treatment. Nature Reviews Microbiology. 14: 320-30. DOI: 10.1038/nrmicro.2016.34.

12. Campos J.L., Garrido J.M., Méndez R., Lema J.M. (2001). Effect of two broadspectrum antibiotics on activity and stability of continuous nitrifying system. Applied Biochemistry and Biotechnology. 95: 1-10. DOI:10.1385/abab:95:1:01

13. Carrera J., Vicent T., Lafuente J. (2004). Effect of influent COD/N ratio on biological nitrogen removal (BNR) from high-strength ammonium industrial wastewater. Process Biochemistry. 39: 2035-41. DOI: 10.1016/j.procbio.2003.10.005

14. Chen C., Li J., Chen P., Ding R., Zhang P., Li X. (2014). Occurrence of antibiotics and antibiotic resistances in soils from wastewater irrigation areas in Beijing and Tianjin, China. Environmental Pollution. 193: 94-101. DOI:10.1016/j.envpol.2014.06.005

15. Chen K., Zhou J.L. (2014). Occurrence and behaviour of antibiotics in water and sediments from the Huangpu River, Shangai, China. Chemosphere. 95: 604-12. DOI:10.1016/j.chemosphere.2013.09.119

16. Conley D.J ., Paerl H.W ., Howarth R.W ., Boesch D.F., Seitzinger S.P., Havens K.E., Lancelot C., Likens G.E. (2009). Controlling Eutrophication: Nitrogen and Phosphorus. Science. 323: 1014-15. DOI: 10.1126/science.1167755

17. Deshpande A.D., Baheti K.G., Chatterjee N.R. (2004). Degradation of $\beta$-lactam antibiotics. Current Science. 87(12): 1684-94.

18. Gajewska M., Jóźwiakowski K., Ghrabi A., Masi F. (2015). Impact of influent wastewater quality on nitrogen removal rates in multistage treatment wetlands. Environmental Science and Pollution Research. 22: 12840-48. DOI: 10.1007/s11356-014$3647-4$

19. Geets J., Boon N., Verstraete W. (2006). Strategies of aerobic ammonia-oxidizing bacteria for coping with nutrient and oxygen fluctuations. FEMS Microbiology Ecology. 58: 1-13. DOI: 10.1111/j.1574-6941.2006.00170.x

20. Gomez J., Mendez R., Lema J.M. (1996). The Effect of Antibiotics on Nitrification Processes. Applied Biochemistry and Biotechnology. 57/58: 869-76.

21. Gomez J., Mendez R., Lema J. (2000). Kinetic Study of Addition of Volatile Organic Compounds to a Nitrifying Sludge. Applied Biochemistry and Biotechnology. 87: 189-202.

22. Hamon P., Villain M., Marrot B. (2014). Determination of sorption properties of micropollutants: What is the most suitable activated sludge inhibition technique to preserve 
the biomass structure? Chemical Engineering Journal. 242: 260-68. DOI:10.1016/j.cej.2013.07.117

23. Heberer T. (2001). Tracking persistent pharmaceutical residues from municipal sewage to drinking water. Journal of Hydrology. 266 (2002): 175-89. DOI:10.1016/S00221694(02)00165-8

24. Homem V., Santos L. (2011). Degradation and removal methods of antibiotics from aqueous matrices-A review. Journal of Environmental Management. 92: 2304-47. DOI:10.1016/j.jenvman.2011.05.023

25. Keener, W. K., Arp, D. J. (1994). Transformations of Aromatic Compounds by Nitrosomonas europaea. Applied and Environmental Microbiology. 60(6): 1914-20.

26. Khunjar W.O., Mackintosh S.A., Skotnicka-Pitak J., Baik S., Aga D.S., Love N.G. (2011). Elucidating the Relative Roles of Ammonia Oxidizing and Heterotrophic Bacteria During the Biotransformation of $17 \alpha$-Ethinylestradiol and Trimethoprim. Environmental Science \& Technology. 45(8): 3605-12. DOI:10.1021/es1037035

27. Kidd K.A.J., Blanchfield K.P., Mills K.H., Palace V.P., Evans R.E., Lazorchak J.M., Flick R.W. (2007). Collapse of a fish population after exposure to a synthetic estrogen. Proceedings of the National Academy of Sciences. 104 (21): 8897-8901. DOI:10.1073/pnas.0609568104

28. Kümmerer K. (2009a). Antibiotics in the aquatic environment - A review - Part I. Chemosphere. 75: 417-34. DOI: 10.1016/j.chemosphere.2008.11.086

29. Kümmerer K. (2009b). Antibiotics in the aquatic environment - A review - Part II. Chemosphere. 75: 435-41. DOI 10.1016/j.chemosphere.2008.12.006

30. Labinghisa R.S., Rollon A.P. (2014). Ampicillin Removal by Polyvinylidene Difluoride $(P V D F)$, Polyethersulfone (PES) and Nylon for Membrane Bioreactor Application. International Journal of Innovation, Management and Technology. 5(2): 105-10. DOI: 10.7763/IJIMT.2014.V5.495

31. Lapworth D.J., Baran N., Stuart M.E., Ward R.S. (2012). Emerging organic contaminants in groundwater: A review of sources, fate and occurrence. Environmental Pollution. 163: 287-303. DOI:10.1016/j.envpol.2011.12.034

32. Laxminarayan R., Van Boeckel T., Teillant A. (2015). The Economic Costs of Withdrawing Antimicrobial Growth Promoters from the Livestock Sector. OECD Food, Agriculture and Fisheries Papers. 78: 1-41. DOI:10.1787/5js64kst5wvl-en 
33. Li B., Zhang T. (2010). Biodegradation and Adsorption of Antibiotics in the Activated Sludge Process. Environmental Science \& Technology. 44: 3468-73. DOI:10.1021/es903490h

34. Li T, Xu X., Fu S., Zhang J., Zhang K., Wang S., Zhao M., Ding W., Wang Q. (2014). Structural elucidation of stress degradation products of ampicillin sodium by liquid chromatography/hybrid triple quadrupole linear ion trap mass spectrometry and liquid chromatography/hybrid quadrupole time-of-flight mass spectrometry. Rapid Communications in Mass Spectrometry. 2014, 28, 1929-36. DOI:10.1002/rcm.6970.

35. Lowry O.H., Rosebrough N.J., Farr A.L., Randall R.J. (1951). Protein measurement with the folin phenol reagent. The Journal of Biological Chemistry. 193: 265-75.

36. Marcelino R.B.P., Andrade L.N., Starling M.C.V.M., Amorim C.C., Barbosa M.L.T., Lopes R.P., Reis B.G., Leão M.M.D. (2016). Evaluation of aerobic and anaerobic biodegradability and toxicity assessment of real pharmaceutical wastewater from industrial production of antibiotics. Brazilian Journal of Chemical. 33(03): 445-52. DOI: 10.1590/0104-6632.20160333s20150136

37. Marshall B.M., Levy S.B. (2011). Food Animals and Antimicrobials: Impacts on Human Health. Clinical Microbiology Reviews. 24 (4): 718-33. DOI:10.1128/CMR.00002-11

38. Martínez F., Favela-Torres E., Gomez J. (2000). Oscillations of exopolymeric composition and sludge volume index in nitrifying flocs. Appl. Biochem. Biotechnol. 87:177-188.

39. Martínez-Hernández S., Texier A-C., Cuervo-López F. de M., Gómez J. (2011). 2Chlorophenol consumption and its effect on the nitrifying sludge. Journal of Hazardous Materials. 185: 1592-95. DOI:10.1016/j.jhazmat.2010.09.100

40. McCarty G.W. (1999). Modes of action of nitrification inhibitors. Biology and Fertility of Soils. 29: 1-9. DOI: 10.1007/s003740050518

41. Meffe R., de Bustamante I. (2014). Emerging organic contaminants in surface water and groundwater: A first overview of the situation in Italy. Science of the Total Environment. 481: 280-95. DOI:10.1016/j.scitotenv.2014.02.053

42. Meiklejohn J. (1953). Iron and the Nitrifying Bacteria. Journal of General Microbiology. 8: 58-65.

43. Michael I., Rizzo L., McArdell C.S., Manaia C.M., Merlin C., Scwartz T., Dagot C., Fatta-Kassinos D. (2013). Urban wastewater treatment plants as hotspots for the release of antibiotics in the environment: A review. Water Research. 47: 957-95. DOI: 10.1016/j.watres.2012.11.027 
44. Mitchell S.M., Ullman J.L., Teel A.L., Watts R. J. (2014 ). pH and temperature effects on the hydrolysis of three $\beta$-lactam. Science of the Total Environment. 466-67: 547-555.

45. Mutiyar P. K., Mittal A. K. (2014). Occurrences and fate of selected human antibiotics in influents and effluents of sewage treatment plant and effluent-receiving river Yamuna in Delhi (India). Environmental Monitoring and Assessment. 186: 541-57. DOI:10.1007/s10661-013-3398-6

46. Naveed S., Mateen N., Nazeer S. (2014). Degradation Studies of Ampicillin in Api and Formulations. Journal of Applied Pharmaceutical Science. 6(3): 314-21.

47. Neu H. C. (1982). Mechanisms of Bacterial Resistance to Antimicrobial Agents, with Particular Reference to Cefotaxime and Other $\beta$-Lactam Compounds. Reviews of Infectious Diseases. 4, Suppl. pp. S288-S299. DOI: 10.1093/clinids/4.Supplement_2.S288

48. Oshiro B.T. (1999). The Semisynthetic Penicillins. Infectious Diseases Update. 6(2): 56-59. DOI: 10.1016/S1068-607X(98)00184-X

49. Pal A., Gin K.Y., Lin A.Y, Reinhard M. (2010). Impacts of emerging organic contaminants on freshwater resources: Review of recent occurrences, sources, fate and effects. Science of the Total Environment. 408: 6062- 69. DOI:10.1016/j.scitotenv.2010.09.026

50. Pérez S., Eichhorn P. Aga D.S. (2005). Sulfamethoxazole, sulfathiazole, and trimethoprim at different stages of sewage treatment. Environmental. Toxicology and Chemistry. 24(6): 1361-67. DOI: 10.1897/04-211R.1

51. Petrie B., Barden R., Kasprzyk-Hordern B. (2015). A review on emerging contaminants in wastewaters and the environment: Current knowledge, understudied areas and recommendations for future monitoring. Water Research. 72: 3-27. DOI:10.1016/j.watres.2014.08.053

52. Roose-Amsaleg C, Laverman A.M. (2016). Do antibiotics have environmental sideeffects? Impact of synthetic antibiotics on biogeochemical processes. Environmental Science and Pollution Research. 23: 4000-12. DOI: 10.1007/s11356-015-4943-3

53. Rosenblatt-Farrell N. (2009). El paisaje de la resistencia a los antibióticos. Salud Pública de México. 51(5): 435-42.

54. Sayavedra-Soto L.A., Gvakharia B., Bottomley P.J., Arp D.J., Dolan M.E. (2010). Nitrification and degradation of halogenated hydrocarbons - a tenuous balance for ammonia-oxidizing bacteria. Applied Microbiology and Biotechnology. 86: 435-44. DOI:10.1007/s00253-010-2454-1 
55. Schmidt I., Sliekers O., Schmid M., Bock E., Fuerst J., Kuenen J.G., Jetten M.S.M., Strous M. (2003). New concepts of microbial treatment processes for the nitrogen removal in wastewater. FEMS Microbiology Reviews. 27: 481- 92. DOI:10.1016/S01686445(03)00039-1

56. Shen L., Xu H., Liu Y. (2011). Microbial characterization of the biofilms developed for treating ampicillin-bearing wastewater. Journal of Environmental Science and Health, Part A. 46(3): 314-22. DOI: 10.1080/10934529.2011.539117

57. Silva C.D., Beristain-Montiel L., Cuervo-López F. de M., Texier A-C. (2014). p-Cresol mineralization and bacterial population dynamics in a nitrifying sequential batch reactor. Journal of Environmental Sciences. 26: 1885-1893. DOI: 10.1016/j.jes.2014.06.033

58. Silva C.D., Cuervo-López F. de M., Gómez J., Texier A-C. (2011a). Nitrite effect on ammonium and nitrite oxidizing processes in a nitrifying sludge. World Journal of Microbiology and Biotechnology (2011) 27:1241-45. DOI: 10.1007/s11274-010-0573-6

59. Silva C.D., Gómez J., Beristain-Cardoso R. (2011b). Simultaneous removal of 2chlorophenol, phenol, p-cresol and p-hydroxybenzaldehyde under nitrifying conditions: Kinetic study. Bioresource Technology. 102: 6464-68. DOI: 10.1016/j.biortech.2011.03.105

60. Silva Luna C.D. (2011). Estudio fisiológico de la nitrificación y oxidación del p-cresol en un consorcio nitrificante. Tesis para obtener el grado de Doctor en Biotecnología. División de Ciencias Biológicas y de la Salud, Unidad Iztapalapa.

61. Stuart M., Lapworth D., Crane E., Hart A. (2012). Review of risk from potential emerging contaminants in UK groundwater. Science of the Total Environment. 416: 1-21. DOI: 10.1016/j.scitotenv.2011.11.072

62. Suárez C., Gudiol F. (2009). Antibióticos betalactámicos. Enfermedades Infecciosas y Microbiología Clínica. 27(2): 116-29. DOI: 10.1016/j.eimc.2008.12.001

63. Tran N.H., Urase T., Kusakabe O. (2009). The characteristics of enriched nitrifier culture in the degradation of selected pharmaceutically active compounds. Journal of Hazardous Materials. 171: 1051-57. DOI:10.1016/j.jhazmat.2009.06.114

64. Tran N.H., Urase T., Ngo H.H., Hu J., Ong S.L. (2013). Insight into metabolic and cometabolic activities of autotrophic and heterotrophic microorganisms in the biodegradation of emerging trace organic contaminants. Bioresourse Technology. 146: 721-31. DOI:10.1016/j.biortech.2013.07.083

65. Tuomanen E. (1986). Phenotypic tolerance: the search for beta-lactam antibiotics that kill nongrowing bacteria. Reviews of Infectious Diseases. 8, Suppl 3: S279-291. DOI:10.1093/clinids/8.supplement_3.s279 
66. Van Boeckel T.P., Gandra S., Ashok A., Caudron Q., Grenfell B.T., Levin S.A., Laxminarayan R. (2014). Global antibiotic consumption 2000 to 2010: an analysis of national pharmaceutical sales data. The Lancet Infectious Diseases. 14(8): 742-50. DOI: 10.1016/S1473- 3099(14)70780-7

67. Watkinson A.J., Murby E.J., Kolpin D.W., Costanzo S.D. (2009). The occurrence of antibiotics in an urban watershed: From wastewater to drinking water. Science of Total Environment. 407: 2711-23. DOI: 10.1016/j.scitotenv.2008.11.059

68. Zepeda A., Ben-Youssef C., Rincón S., Cuervo-López F., Gómez J. (2013) Complete and simultaneous removal of ammonium and m-cresol in a nitrifying sequencing batch reactor. Biodegradation. 24:377-85. DOI: 10.1007/s 10532-012-9595-0

69. Zhou P., Su C., Li B., Qian Y. (2006). Treatment of High-Strength Pharmaceutical Wastewater and Removal of Antibiotics in Anaerobic and Aerobic Biological Treatment Processes. Journal of Environmental Engineering. 132 (1): 129-136. DOI: 10.1061/(ASCE)0733-9372(006)132:1(129)

70. Zuccato E., Castiglioni S., Bagnati R., Melis M., Fanelli R. (2010). Source, occurrence and fate of antibiotics in the Italian aquatic environment. Journal of Hazardous Materials. 179: 1042-48. DOI: 10.1016/j.jhazmat.2010.03.110 
$\begin{array}{lr}\text { Fecha : } & 31 / 05 / 2018 \\ \text { Página : } & 1 / 1\end{array}$

\title{
CONSTANCIA DE PRESENTACION DE EXAMEN DE GRADO
}

\begin{abstract}
La Universidad PRESENTACION DE RAMIREZ MUÑOZ,

Autónoma Metropolitana extiende la presente CONSTANCIA DE EXAMEN DE GRADO de MAESTRO EN BIOTECNOLOGIA del alumno JOSE JUAN matrícula 2143802682, quien cumplió con los 140 créditos correspondientes a las unidades de enseñanza aprendizaje del plan de estudio. Con fecha primero de junio del 2018 presentó la DEFENSA de su EXAMEN DE GRADO CuYa denominación es:
\end{abstract}

CAPACIDAD DE UN CONSORCIO NITRIFICANTE PARA BIOTRANSFORMAR LA AMPICILINA

Cabe mencionar que la aprobación tiene un valor de 40 créditos y el programa consta de 180 créditos.

El jurado del examen ha tenido a bien otorgarle la calificación de:

Aprobar

JURADO

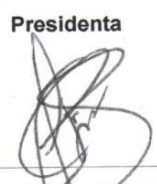

CUERVO LOPEZ

Vocal

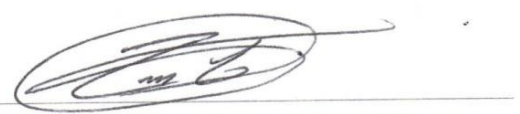

DR. CARLOS DAVID SILVA LUNA

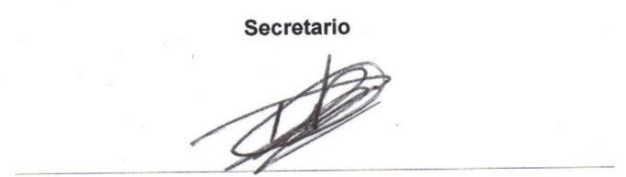

DR. DIEGO IVAN BEJARANO ORTIZ

Vocal

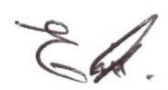

DRA. EMIR MARTINEZ GUTIERREZ 